\title{
A Macroeconomic Model with Financially Constrained Producers and Intermediaries *
}

\author{
Vadim Elenev \\ NYU Stern
}

\author{
Tim Landvoigt \\ UT Austin
}

\author{
Stijn Van Nieuwerburgh \\ NYU Stern, NBER, and CEPR
}

February 15, 2016

\begin{abstract}
We solve a general equilibrium model with three types of agents and a government. Borrower-entrepreneurs produce output financed with long-term debt issued by financial intermediaries, subject to a leverage constraint. Intermediaries fund these loans combining deposits and their own equity, and are subject to a regulatory capital constraint. Savers provide funding to banks and to the government. Both entrepreneurs and banks make optimal default decisions. The government issues debt to finance budget deficits and to pay for bank rescue operations. We solve for macroeconomic quantities, the price of capital, the yield on safe bonds, and the credit spread. We study how financial and non-financial recessions differ, show that high credit spread forecasts future declines in economic activity, and study macro-prudential policies. Policies that limit corporate leverage and financial leverage reduce welfare. Their benefits for financial and macro-economic stability are outweighed by the costs from a smaller-sized economy. The two types of macroprudential policies have different implications for the wealth distribution.
\end{abstract}

JEL: G12, G15, F31.

Keywords: financial intermediation, production, government bailouts

*First draft: February 15, 2016. We thank Pierre Mabille for excellent research assistance. 


\section{Introduction}

The financial crisis and Great Recession of 2007-09 underscored the importance of the financial system for the broader economy. Borrower default rates, bank insolvencies, government bailouts, and credit spreads all spiked while real interest rates were very low. The disruptions in financial intermediation fed back on the real economy. Consumption, investment, and output all fell substantially and persistently.

These events have caused economists to revisit the role of the financial sector in models of the macro economy. Building on early work that emphasized the importance of endogenous developments in credit markets in amplifying business cycle shocks, ${ }^{1}$ a second generation of models has added nonlinear dynamics and a richer financial sector. ${ }^{2}$ While a lot of progress has been made in understanding how financial intermediaries affect asset prices and macroeconomic performance, an important remaining challenge is to deliver a quantitatively successful model that can capture the dynamics of financial intermediary capital, asset prices, and the real economy observed during credit crises. Such a model requires a government, so that possible crisis responses can be studied, and explicit and implicit government guarantees to the financial sector can be incorporated. Indeed, Central Banks are in search of a model of the financial sector that can be integrated into their existing quantitative macro models. Our paper aims to make progress on this important agenda. It provides a calibrated model that matches key features of the U.S. macroeconomy and asset prices. In addition, we make three methodological contributions.

First, we separate out the role of producers and banks. The existing literature, as exemplified by the seminal Brunnermeier and Sannikov (2014) paper, usually combines the roles of financial intermediaries and producers ("experts"). This setup assumes frictionless interaction between banks and borrowers and focuses on the interaction between experts and saving households. It assumes that financial intermediaries hold equity claims in productive firms. In reality, banks make corporate loans and hold corporate bonds which are debt claims. ${ }^{3}$ These debt contracts

\footnotetext{
${ }^{1}$ E.g., Bernanke and Gertler (1989), Bernanke, Gertler, and Gilchrist (1996), Bernanke, Gertler, and Gilchrist (1999), Kiyotaki and Moore (1997), and Gertler and Karadi (2011).

${ }^{2}$ E.g., Brunnermeier and Sannikov (2014), He and Krishnamurthy (2012), He and Krishnamurthy (2013), Gârleanu and Pedersen (2011), Adrian and Boyarchenko (2012), Maggiori (2013), Moreira and Savov (2016).

${ }^{3}$ It is well understood that debt-like contracts arise in order to reduce the cost of gathering information and to mitigate principal-agent problems. See for example Dang, Gorton, and Holmstrom (2015).
} 
are subject to default risk of the borrowers. Our model has three groups of agents, each with their own balance sheet: depositors who lend to intermediaries, entrepreneurs who own the production technology and borrow from intermediaries, and intermediaries who own the banks. Banks perform the traditional role of liquidity transformation and bear the credit risk in the economy. They help to optimally allocate risk across the various agents in the economy. Motivated by standard agency frictions, entrepreneurs/firms' borrowing capacity is limited by the equilibrium value of their capital stock. The maximum loan-to-value at loan origination is a first key macroprudential policy parameter. In order to discipline banks, we model a Basel II/III-style regulatory capital requirement that limits banks' liabilities at a fraction of their risk-weighted assets. The minimum regulatory capital that banks must hold is a second key macroprudential policy parameter.

Our second contribution is to introduce the possibility of default for financial intermediaries. The existing literature is usually cast in continuous time. As the financial sector approaches insolvency, intermediaries reduce risk and prices adjust so that they never go bankrupt. In discrete time, the language of quantitative macroeconomics, the possibility of default of intermediaries cannot be avoided. Far from a technical detail, bank insolvency is an important reality that keeps policy makers up at night. As Reinhart and Rogoff (2009) and Jorda, Schularick, and Taylor (2014a) make clear, banks frequently become insolvent. When they do, the banks' creditors (mostly the depositors) are bailed out by the government. In our model we assume that banks have limited liability and choose to default optimally. When the market value of their assets falls below that of liabilities, the government steps in, liquidates the assets and makes whole the depositors. The banking sector starts afresh the next period with zero wealth. The expectation of a bailout affects banks' risk taking incentives (e.g., Farhi and Tirole (2012)). By allowing for the possibility of bank insolvencies, our model can help explain how a corporate default wave can trigger financial fragility. Vice versa, weak financial balance sheets reduce firms' ability to borrow, invest, and grow.

The third methodological contribution is to endogenize the risk-free interest rate on safe debt. Most models in the intermediary-based macro and asset pricing literature keep the interest rate on safe assets (deposits or government debt) constant, sometimes by virtue of an assumption of risk neutrality of the savers. Once savers are risk averse, a natural assumption 
given that they invest in guaranteed deposits, the dynamics of the model change dramatically. In a crisis, intermediaries contract the size of their balance sheet, thereby reducing the supply of safe debt in the economy. Simultaneously, risk averse depositors with strong precautionary savings motives increase savings, thereby increasing the demand for safe assets. As a result, the equilibrium quantity of safe debt changes little but the price increases substantially. Real interest rates may turn negative. The low cost of debt allows the intermediaries to recapitalize quickly, dampening the initial crisis. The endogenous price response of safe debt short-circuits the amplification mechanism usually arising in a balance sheet recession in these models. One might argue that there are other investors in the market for safe assets whose demand for safe assets may not rise as much because they are less risk averse (maybe institutional investors), but their demand for safe debt would have to be negatively correlated with that of the risk averse savers. Foreigners' demand for U.S. safe debt also increased dramatically in the global financial crisis, further amplifying domestic demand by savers rather than offsetting it. We argue that the solution lies in carefully modeling the government side of the model. With countercyclical transfer spending and procyclical tax revenues, the government deficit is highly countercyclical. This expands the supply of safe debt in bad times, offsetting or even reversing the contraction in the supply of private safe debt, at the same time that the demand expands. While rates may still fall in crises, the decline is not as large as it would be without the government sector, largely restoring the amplification of the balance sheet recession models. Importantly, because the risk averse saver must absorb more debt in bad times, she must reduce spending in high marginal utility states. The ex-ante precautionary savings effect this triggers reduces the unconditional mean interest rate in the economy. While they may still be desirable for aggregate welfare, a new insight is that automatic stabilizers in fiscal policy slow down the recapitalization of banks in a crisis.

What results is a rich and quantitatively relevant framework of the interaction between four balance sheets: those of borrower-entrepreneurs, financial intermediaries, households, and the government. Our model features occasionally binding borrowing constraints for both borrowerentrepreneurs and for intermediaries, and allows for bankruptcy of both borrowers and intermediaries. The model generates amplification whereby aggregate shocks, for example to productivity, not only directly affect production and investment, but also affect the financial 
and non-financial sectors' leverage. Tighter financial constraints on banks reduce the availability of credit to firms which hurts investment and output, beyond the effects familiar from standard accelerator models.

Our model quantitatively matches the maturity, default risk, and loss-given default of corporate debt. It generates a large credit spread. We use the model to study the differences between regular non-financial recessions and financial recessions, which are recessions that coincide with credit crisis. We also show that credit spreads predict future economic activity, as has been emphasized in the recent literature. ${ }^{4}$ Our second main exercise is to investigate the quantitative effects of macro-prudential policies for financial stability, economic growth, economic stability, fiscal stability, and economy-wide welfare. We compare and contrast bank capital regulation and loan-to-value limits on borrowers. Our model belongs to the class of models where incomplete markets and borrowing constraints create room for macro-prudential policy intervention. ${ }^{5}$

Our paper provides a state-of-the-art solution technique. The model has two exogenous and persistent sources of aggregate risk. Standard TFP shocks hit the productions function. In addition, shocks to the cross-sectional dispersion of capital depreciation govern credit risk. The model also has five endogenous aggregate state variables: the capital stock, corporate debt stock, intermediary net worth, household wealth, and the government debt stock. To solve this complex problem, we provide a nonlinear global solution method, called policy time iteration, which is a variant of the parameterized expectations approach. Policy functions, prices, and Lagrange multipliers are approximated as piecewise linear functions of the exogenous and endogenous state variables. The algorithm solves for a set of nonlinear equations including the Euler equations and the Kuhn-Tucker conditions expressed as equalities. ${ }^{6}$ Our method improves on existing methods which compute two non-stochastic steady states: one steady state when the constraint never binds and one where it always binds, and then linearizes the

\footnotetext{
${ }^{4}$ See for example, Friedman and Kuttner (1993), Gilchrist and Zakrajsek (2012), Greenwood and Hanson (2013), Jorda, Schularick, and Taylor (2014b), Lopez-Salido, Stein, and Zakrajsek (2015), Krishnamurthy and Muir (2016), and Mian, Sufi, and Verner (2016).

${ }^{5}$ Other models in this class are Lorenzoni (2008), Mendoza (2010), Korinek (2012), Bianchi and Mendoza (2013), Bianchi and Mendoza (2015), and Guerrieri and Lorenzoni (2015). Farhi and Werning (2014) study macroprudential policy in a model with demand externalities.

${ }^{6}$ One output of this research project will be a set of computer code which will be made publicly available. Discussions with the research department at three different Central Banks indicate that there is a demand for this type of output.
} 
solution around both of these states (Guerrieri and Iacoviello (2015)). Agents in the model do not take into account the fact that borrowing constraints may become binding in the future due to future shock realizations. As a result, the approach ignores agents' precautionary savings motives related to future switches between "regimes" with and without binding constraints. While the piecewise-linear solution may prove sufficiently accurate in some contexts, it remains an open question whether it offers an appropriate solution to models with substantial risk and higher risk aversion, designed to match not only macroeconomic quantities but also asset prices (risk premia).

The rest of the paper is organized as follows. Section 2 discusses the model setup. Section 3 presents the calibration. Section 4 contains the main results. Section 5 uses the model to study various macro-prudential policies. Section 6 concludes. All model derivations and some details on the calibration are relegated to the appendix.

\section{The Model}

\subsection{Preferences, Technology, Timing}

Preferences The model features a government and three groups of households: borrowerentreprenuers (denoted by superscript B), and two types of savers, differentiated by their risk aversion coefficients. We refer to the less risk averse savers as "intermediaries" (denoted by superscript I) and the more risk averse simply as "savers" (denoted by S). Borrower-entrepreneurs are less patient than savers, implying for the discount factors that $\beta_{B}<\beta_{I} \leq \beta_{S}$. For the coefficient of relative risk aversion we assume that $\sigma_{I}<\sigma_{B} \leq \sigma_{S}$. All agents have Epstein-Zin preferences over consumption streams $\left\{C_{t}^{j}\right\}_{t=0}^{\infty}$ with intertemporal elasticity of substitution $\nu$.

$$
U_{t}^{j}=\left\{(1-\beta)\left(C_{t}^{j}\right)^{1-1 / \nu}+\beta_{j}\left(\mathrm{E}_{t}\left[\left(U_{t+1}^{j}\right)^{1-\sigma_{j}}\right]\right)^{\frac{1-1 / \nu}{1-\sigma_{j}}}\right\}^{\frac{1}{1-1 / \nu}}
$$

for $j=B, I, S$. 
Technology Borrower-entrepreneurs own the productive capital stock of the economy and operate its production technology of the form

$$
Y_{t}=\left(K_{t}\right)^{(1-\alpha)}\left(Z_{t} L_{t}\right)^{\alpha},
$$

where $K_{t}$ is capital, $L_{t}$ is labor, and $Z_{t}$ is labor productivity. We assume that productivity grows at a stochastic rate $g_{t}$ which follows an $\mathrm{AR}(1)$ process.

In addition to the technology for producing consumption goods, borrower-entrepreneurs also have access to a technology that can turn consumption into capital goods.

Borrower-entrepreneurs, intermediaries, and savers are endowed with $\bar{L}^{B}, \bar{L}^{I}$ and $\bar{L}^{S}$ units of labor, respectively. We assume that all types of households supply their complete labor endowment inelastically.

There are two more assets in the economy. One risky long-term bond that borrowerentrepreneurs can issue to intermediaries, and one short-term risk free bond that intermediaries can issue to savers.

Timing The timing of agents' decisions at the beginning of period $t$ is as follows:

1. Aggregate TFP and stochastic depreciation shocks for borrower-entrepreneurs are realized. Production occurs.

2. Intermediaries decide on a bankruptcy policy. In case of a bankruptcy, their financial wealth is set to zero and they incur a utility penalty. At the time of the decision, the magnitude of the penalty is unknown. ${ }^{7}$ Savers know its probability distribution and maximize expected utility by specifying a binding decision rule for each possible realization of the penalty. ${ }^{8}$

3. Borrower households decide what fraction of debt to default on.

\footnotetext{
${ }^{7}$ Introducing a random utility penalty is a technical assumption we make for tractability. It makes the value function differentiable and allows us to use our numerical methods which rely on this differentiability. This randomization assumption is common in labor market models (Hansen (1985)).

${ }^{8}$ The assumption of making a binding default decision is necessitated in the presence of Epstein-Zin preferences.
} 
4. Intermediaries' utility penalty shock is realized and they follow their bankruptcy decision rule from step 2. In case of bankruptcy, the government picks up the shortfall in repayments to debt holders (depositors).

5. All agents solve their consumption and portfolio choice problems. Markets clear. All agents consume.

Each agent's problem depends on the wealth of others; the entire wealth distribution is a state variable. Each agent must forecast how that state variable evolves, including the bankruptcy decisions of borrowers and intermediaries. We now describe each of the three types of household problems and the government problem in detail.

\subsection{Borrower-Entrepreneurs' Problem}

There is a representative family of borrower-entrepreneurs, consisting of a measure one of members. Each member owns the same quantity of capital $k_{t}^{B}$ s.t. $\int_{0}^{1} k_{t}^{B} d i=K_{t}^{B}$, and the same quantity of outstanding bonds $a_{t}^{B}$ s.t. $\int_{0}^{1} a_{t}^{B} d i=A_{t}^{B}$. The bond is a long-term contract, modeled as a perpetuity. Bond coupon payments decline geometrically, $\left\{1, \delta, \delta^{2}, \ldots\right\}$, where $\delta$ captures the duration of the bond. We introduce a "face value" $F=\frac{\theta}{1-\delta}$, a fixed fraction $\theta$ of all repayments for each bond issued. Per definition, interest payments are the remainder $\frac{1-\theta}{1-\delta}$.

At the time of production, borrower-entrepreneurs hire their own labor and the labor of intermediaries and savers, denoted by $L_{t}^{j}$, with $j=B, I, S$. As payment each group receives a competitive wage $w_{t}^{j}$ per unit of labor. During production, the labor inputs of the three types are combined into aggregate labor:

$$
L_{t}=\left(L_{t}^{B}\right)^{1-\gamma_{S}-\gamma_{I}}\left(L_{t}^{S}\right)^{\gamma_{S}}\left(L_{t}^{I}\right)^{\gamma_{I}}
$$

Capital used for production are all capital units jointly held by borrower-entrepreneurs at the beginning of the period, such that output is $Y_{t}=\left(K_{t}^{B}\right)^{(1-\alpha)}\left(Z_{t} L_{t}\right)^{\alpha}$.

During the production process, the capital units owned by individual borrower-entrepreneurs experience depreciation shocks. Each borrower-member draws an idiosyncratic depreciation shock $\omega_{i, t} \sim F_{\omega}(\cdot)$ which proportionally lowers the amount of capital by $\left(1-\omega_{i, t}\right) k_{t}^{B}$. The 
capital left after stochastic depreciation is $\omega_{i, t} k_{t}^{B}$. We denote the cross-sectional mean and standard deviation by $\mu_{\omega}=\mathrm{E}_{i}\left[\omega_{i, t}\right]$ and $\sigma_{t, \omega}=\left(\operatorname{Var}_{i}\left[\omega_{i, t}\right]\right)^{0.5}$, where the latter varies over time. The mean implies an average depreciation rate of capital of $\delta_{K}=1-\mu_{\omega}$.

The family of borrower-entrepreneurs jointly decides which members should default on their outstanding debt. The capital units owned by the members who default are turned over to (seized by) the lender. Let the function $\iota(\omega):[0, \infty) \rightarrow\{0,1\}$ indicate the borrowerentrepreneurs' decision to default on a capital unit of quality $\omega$. We conjecture and later verify that the optimal default decision is characterized by a threshold level $\omega_{t}^{*}$, such that borrowerentrepreneurs default on all capital units with $\omega_{i, t} \leq \omega_{t}^{*}$ and repay the debt for all other capital. Using the threshold level $\omega_{t}^{*}$, we define $Z_{A}\left(\omega_{t}^{*}\right)$ to be the fraction of debt repaid to lenders and $Z_{K}\left(\omega_{t}^{*}\right) p_{t} K_{t}^{B}$ to be the value of the capital stock to the borrowers after default decisions have been made, where:

$$
\begin{aligned}
& Z_{A}\left(\omega_{t}^{*}\right)=\int_{0}^{\infty}(1-\iota(\omega)) f_{\omega}(\omega) d \omega=\operatorname{Pr}\left[\omega_{i, t} \geq \omega_{t}^{*}\right], \\
& Z_{K}\left(\omega_{t}^{*}\right)=\int_{0}^{\infty}(1-\iota(\omega)) \omega f_{\omega}(\omega) d \omega=\operatorname{Pr}\left[\omega_{i, t} \geq \omega_{t}^{*}\right] \mathrm{E}\left[\omega_{i, t} \mid \omega_{i, t} \geq \omega_{t}^{*}\right]
\end{aligned}
$$

After making a coupon payment of 1 per unit of remaining outstanding debt, the amount of outstanding debt declines to $\delta Z_{A}\left(\omega_{t}^{*}\right) A_{t}^{B}$.

In addition to producing consumption goods, borrower-entrepreneurs jointly produce capital goods from consumption goods. In order to create $X_{t}$ new capital units, the required input of consumption goods is

$$
X_{t}+\Psi\left(X_{t} / K_{t}^{B}\right) K_{t}^{B}
$$

with $\Psi^{\prime \prime}()>0, \Psi\left(e^{\bar{g}}-\mu_{\omega}\right)=0$, and $\Psi^{\prime}\left(e^{\bar{g}}-\mu_{\omega}\right)=0$.

The profit of the borrower-entrepreneur's business is subject to a tax with rate $\tau_{\Pi}^{B}$. The profit for tax purposes is defined as sales revenue net of labor expenses, and capital depreciation and interest payments of surviving entrepreneurs

$$
\Pi_{t}^{B}=Y_{t}-\sum_{j=B, I, S} w_{t}^{j} L_{t}^{j}-\delta_{K} Z_{A}\left(\omega_{t}^{*}\right) p_{t} K_{t}^{B}-(1-\theta) Z_{A}\left(\omega_{t}^{*}\right) A_{t}^{B}
$$


The fact that interest expenditure $(1-\theta) Z_{A}\left(\omega_{t}^{*}\right) A_{t}^{B}$ is deducted from taxable profit creates a "tax shield" and hence a preference for debt funding.

The borrower-entrepreneur family's problem is to choose consumption $C_{t}^{B}$, capital for next period $K_{t+1}^{B}$, default threshold $\omega_{t}^{*}$, new debt $A_{t+1}^{B}$, investment $X_{t}$ and labor inputs $L_{t}^{j}$ to maximize life-time utility $U_{t}^{B}$ in (1), subject to the budget constraint:

$$
\begin{gathered}
C_{t}^{B}+X_{t}+\Psi\left(X_{t} / K_{t}^{B}\right) K_{t}^{B}+Z_{A}\left(\omega_{t}^{*}\right) A_{t}^{B}\left(1+\delta q_{t}^{m}\right)+p_{t} K_{t+1}^{B}+\sum_{j=B, I, S} w_{t}^{j} L_{t}^{j}+\tau_{\Pi}^{B} \Pi_{t}^{B} \\
\leq Y_{t}+\left(1-\tau_{t}^{B}\right) w_{t}^{B} \bar{L}^{B}+p_{t}\left(X_{t}+Z_{K}\left(\omega_{t}^{*}\right) K_{t}^{B}\right)+q_{t}^{m} A_{t+1}^{B}+G_{t}^{T, B}
\end{gathered}
$$

and a leverage constraint:

$$
F A_{t+1}^{B} \leq \phi p_{t} Z_{K}\left(\omega_{t}^{*}\right) K_{t}^{B}
$$

Outstanding debt at the end of the period $A_{t+1}^{B}$ is the sum of the remaining debt after default and new borrowing. The borrower household uses after-tax labor income, net transfer income from the government $\left(G_{t}^{T, B}\right)$, sales of old $\left(K_{t}^{B}\right)$ and newly produced $\left(X_{t}\right)$ capital units, and new debt raised, to pay for consumption, debt service, new capital purchases, investment including

adjustment costs, and wage payments. New debt raised is $q_{t}^{m} A_{t+1}^{B}$, where $q_{t}^{m}$ is the price of one bond in terms of the consumption good.

The borrowing constraint in (7) caps the face value of debt at the end of the period, $F A_{t+1}^{B}$, to a fraction of the market value of the available capital units after depreciation and default, $p_{t} Z_{K}\left(\omega_{t}^{*}\right) K_{t}^{B}$, where $\phi$ is the maximum leverage ratio. With such a constraint, declines in capital prices (in bad times) tighten borrowing constraints.

\subsection{Savers}

Savers can invest in one-period risk free bonds (deposits and government debt). They inelastically supply their unit of labor $\bar{L}^{S}$. Entering with wealth $W_{t}^{S}$, the saver's problem is to choose consumption $C_{t}^{S}$ and short-term bonds $B_{t}^{S}$ to maximize life-time utility $U_{t}^{S}$ in (1), subject to the budget constraint:

$$
C_{t}^{S}+q_{t}^{f} B_{t}^{S} \leq\left(1-\tau_{t}^{S}\right) w_{t}^{S} \bar{L}^{S}+G_{t}^{T, S}+W_{t}^{S}
$$


and a short-sale constraints on bond holdings:

$$
B_{t}^{S} \geq 0
$$

The budget constraint (8) shows that saver uses after-tax labor income, net transfer income, and beginning-of-period wealth to pay for consumption, and purchases of short-term bonds

\section{$2.4 \quad$ Intermediaries}

After TFP and depreciation shocks have been realized, financial intermediaries choose whether or not to declare bankruptcy. Intermediaries who declare bankruptcy have all their assets and liabilities liquidated. They also incur a stochastic utility penalty $\rho_{t}$, with $\rho_{t} \sim F_{\rho}$, i.i.d. over time and independent of all other shocks. At the time of the bankruptcy decision, intermediaries do not yet know the realization of the bankruptcy penalty. Rather, they have to commit to a bankruptcy decision rule $D(\rho): \mathbb{R} \rightarrow\{0,1\}$, that specifies the optimal decision for every possible realization of $\rho_{t}$. Intermediaries choose $D(\rho)$ to maximize expected utility at the beginning of the period. We conjecture and later verify that the optimal default decision is characterized by a threshold level $\rho_{t}^{*}$, such that intermediaries default for all realizations for which the utility cost exceeds the threshold.

After the realization of the penalty, intermediaries execute their bankruptcy choice according to the decision rule. They then face a consumption and portfolio choice problem to be described below. First, while intertemporal preferences are still specified by equation (1), intraperiod utility $u_{t}^{j}$ depends on the bankruptcy decision and penalty:

$$
u_{t}^{I}=\frac{C_{t}^{I}}{\exp \left(D\left(\rho_{t}\right) \rho_{t}\right)} .
$$

Intermediaries' portfolio choice consists of loans to borrower-entrepreneurs $\left(A_{t}^{I}\right)$ and short-term bonds $\left(B_{t}^{I}\right)$. Loans are modeled as bonds aggregating the debt of the borrowers. The coupon payment on performing loans in the current period is $A_{t}^{I} Z_{A}\left(\omega_{t}^{*}\right)$. For borrower-entrepreneurs that enter into foreclosure, the intermediaries repossess their capital units as collateral. These capital units are worth $(1-\zeta)\left(\mu_{\omega}-Z_{K}\left(\omega_{t}^{*}\right)\right) p_{t} K_{t}^{B}$, where $\zeta$ is the fraction of capital value 
destroyed in bankruptcy, a deadweight loss. Thus, the total payoff per bond is:

$$
M_{t}=Z_{A}\left(\omega_{t}^{*}\right)+\frac{(1-\zeta)\left(\mu_{\omega}-Z_{K}\left(\omega_{t}^{*}\right)\right) p_{t} K_{t}^{B}}{A_{t}^{I}} .
$$

The price of the bond is $q_{t}^{m}$. In addition, intermediaries can trade in short-term bonds with savers and the government. They are allowed to take a short position in these bonds, using their loans to borrower-entrepreneurs as collateral. They are subject to a leverage constraint:

$$
-q_{t}^{f} B_{t}^{I} \leq q_{t}^{m} \xi A_{t+1}^{I}
$$

A negative position in the short-term bond is akin to intermediaries issuing deposits. The negative position in the short-term bond must be collateralized by the market value of the risk taker's holdings of long-term loan bonds. The parameter $\xi$ determines how useful loans are as collateral.

Denote the wealth of an intermediary that did not go into bankruptcy by:

$$
W_{t}^{I}=\left(M_{t}+\delta Z_{A}\left(\omega_{t}^{*}\right) q_{t}^{m}\right) A_{t}^{I}+B_{t-1}^{I}
$$

Intermediaries are subject to corporate profit taxes at rate $\tau_{\Pi}^{I}$. Their profit for tax purposes is defined as the net interest income on their loan business ${ }^{9}$

$$
\Pi_{t}^{I}=(1-\theta) Z_{A}\left(\omega_{t}^{*}\right) A_{t}^{I}+r_{t}^{f} B_{t-1}^{I}
$$

Intermediaries' also receive income for inelastically supplying their labor to borrower-entrepreneurs ${ }^{10}$. They further need to pay a deposit insurance fee to the government that is proportional to the amount of short-term bonds they issue. Their budget constraint is

$$
\left(1-D\left(\rho_{t}\right)\right) W_{t}^{I}+\left(1-\tau^{I}\right) w_{t}^{I} \overline{L^{I}}+G_{t}^{T, I} \geq C_{t}^{I}+q_{t}^{m} A_{t+1}^{I}+\left(q_{t}^{f}+\mathrm{I}_{\left\{B_{t}^{I}<0\right\}} \kappa\right) B_{t}^{I}+\tau_{\Pi}^{I} \Pi_{t}^{I} .
$$

Note that intermediaries only receive wealth $W_{t}^{I}$ if they do not declare bankruptcy at the

\footnotetext{
${ }^{9}$ We define the risk free interest rate as the yield on risk free bonds, $r_{t}^{f}=1 / q_{t}^{f}-1$.

${ }^{10}$ Stand-in for managerial labor or similar.
} 
beginning of the period; in case of bankruptcy their wealth is zero.

\subsection{Government}

The actions of the government are determined via fiscal rules: taxation, spending, bailout, and debt issuance policies. Government tax revenues, $T_{t}$, are labor income tax receipts plus deposit insurance fee receipts and corporate profit tax receipts:

$$
T_{t}=\sum_{j=B, I, S} \tau_{t}^{j} w_{t}^{j} L_{t}^{j}+\tau_{\Pi}^{B} \Pi_{t}^{B}+\tau_{\Pi}^{I} \Pi_{t}^{I}-\mathrm{I}_{\left\{B_{t}^{I}<0\right\}} \kappa B_{t}^{I}
$$

Government expenditures, $G_{t}$ are the sum of financial sector bailouts, other exogenous government spending, $G_{t}^{o}$, and transfer spending $G_{t}^{T}$ :

$$
G_{t}=G_{t}^{o}+G_{t}^{T}-D\left(\rho_{t}\right) W_{t}^{I}
$$

The bailout to the financial sector equals the negative of the financial wealth of intermediaries, $W_{t}^{I}$, in the event of a bankruptcy.

The government issues one-period risk-free debt. Debt repayments and government expenditures are financed by new debt issuance and tax revenues, resulting in the budget constraint:

$$
B_{t-1}^{G}+G_{t} \leq q_{t}^{f} B_{t}^{G}+T_{t}
$$

We impose a transversality condition on government debt:

$$
\lim _{u \rightarrow \infty} \mathrm{E}_{t}\left[\tilde{\mathcal{M}}_{t, t+u}^{S} B_{t+u}^{G}\right]=0
$$

where $\tilde{\mathcal{M}}^{S}$ is the SDF of the saver. ${ }^{11}$

Because of its unique ability to tax and repay its debt, the government can spread out the cost of default waves and financial sector rescue operations over time.

\footnotetext{
${ }^{11}$ We show below that the risk averse saver is the marginal agent for short-term risk-free debt. In the numerical work below, we keep the ratio of government debt to GDP contained between $\underline{b^{G}}$ and $\overline{b^{G}}$ by decreasing taxes linearly when the debt-to-GDP threatens to fall below $\underline{b^{G}}$ and raising taxes linearly when debt-to-GDP threatens to exceed $\overline{b^{G}}$.
} 
Government policy parameters are $\Theta_{t}=\left(\tau_{t}^{i}, \tau_{\Pi}^{i}, \kappa, G_{t}^{o}, \phi, \xi\right)$. The parameters $\phi$ in equation (7) and $\xi$ in equation (10) can be thought of as macro-prudential policy tools. One could add the parameters that govern the utility cost of bankruptcy of intermediaries to the set of policy levers, since the government may have some ability to control the fortunes of the financial sector in the event of a bankruptcy.

\subsection{Equilibrium}

Given a sequence of income shocks $\left\{Y_{t}\right\}$, depreciation shocks $\left\{\omega_{t, i}\right\}_{i \in B}$, and utility costs of default shocks $\rho_{t}$, and given a government policy $\Theta_{t}$, a competitive equilibrium is an allocation $\left\{C_{t}^{B}, K_{t+1}^{B}, X_{t}, A_{t+1}^{B}, L_{t}^{j}\right\}$ for borrower-entrepreneurs, $\left\{C_{t}^{S}, B_{t}^{S}\right\}$ for savers, $\left\{C_{t}^{I}, A_{t+1}^{I}, B_{t}^{I}\right\}$ for intermediaries, default policies $\iota\left(\omega_{i t}\right)$ and $D\left(\rho_{t}\right)$, and a price vector $\left\{p_{t}, q_{t}^{m}, q_{t}^{f}\right\}$, such that given the prices, borrower-entrepreneurs, savers, and intermediaries maximize life-time utility subject to their constraints, the government satisfies its budget constraint, and markets clear.

The market clearing conditions are:

1. Risk-free bonds: $B_{t}^{G}=B_{t}^{S}+B_{t}^{I}$

2. Loans: $A_{t+1}^{B}=A_{t+1}^{I}$

3. Capital: $K_{t+1}^{B}=\mu_{\omega} K_{t}^{B}+X_{t}$

4. Labor: $L_{t}^{j}=\bar{L}^{j}$ for all $j=B, I, S$

5. Consumption: $Y_{t}=C_{t}^{B}+C_{t}^{I}+C_{t}^{S}+G_{t}^{o}+X_{t}+K_{t}^{B} \Psi\left(X_{t} / K_{t}^{B}\right)+\zeta\left(\mu_{\omega}-Z_{K}\left(\omega_{t}^{*}\right)\right) p_{t} K_{t}^{B}$

The last equation states that total output equal the sum of consumption expenditures, (wasteful) spending by the government, consumption goods used for capital-goods production, and intermediary expenditure incurred when liquidating capital goods of bankrupt firms ${ }^{12}$.

\footnotetext{
${ }^{12}$ This assumption implies that intermediaries need to spend a fraction $\zeta$ of the fair value of the capital to execute the distressed sale
} 


\subsection{Welfare}

In order to compare economies that differ in the policy parameter vector $\Theta_{t}$, we must take a stance on how to weigh the different agents. We propose a utilitarian social welfare function summing value functions of the agents according to their population weights $\ell$ :

$$
\mathcal{W}_{t}\left(\cdot ; \Theta_{t}\right)=\ell^{B} V_{t}^{B}+\ell^{D} V_{t}^{D}+\ell^{I} V_{t}^{I},
$$

where the $V^{j}(\cdot)$ functions are the value functions defined in the appendix.

\section{Calibration}

The model is calibrated at annual frequency. The parameters of the model and their targets are summarized in Table 1.

Aggregate Productivity We assume that aggregate productivity grows with a stochastic rate $g_{t}$ that follows an $\mathrm{AR}(1)$ process:

$$
\begin{aligned}
& Z_{t+1}=\exp \left(g_{t+1}\right) Z_{t} \\
& g_{t+1}=\left(1-\rho_{g}\right) \bar{g}+\rho_{g} g_{t}+\epsilon_{t+1} \quad \epsilon_{t+1} \sim \text { iid } \mathcal{N}\left(0, \sigma_{g}\right)
\end{aligned}
$$

Given the persistence of income growth, $g_{t}$ becomes a state variable. We discretize the $g_{t}$ process into a 5-state Markov chain using the method of Rouwenhorst (1995). The procedure matches the mean, volatility, and persistence of GDP growth, which is endogenous, by choosing both the productivity grid points and the transition probabilities between them. Consistent with our model, our concept of GDP excludes net exports, housing investment, changes in inventories, and government investment. We define the GDP deflator correspondingly. The observed real per capita GDP growth between 1953 and 2014 has a mean of $2.00 \%$, a volatility of $1.94 \%$ and a persistence of 0.34 . 
Table 1: Calibration

This table reports parameter values.

\begin{tabular}{|c|c|c|c|}
\hline Par & Description & Value & Target \\
\hline \multicolumn{4}{|c|}{ Exogenous Shocks } \\
\hline $\bar{g}$ & mean TFP growth & $2.0 \%$ & Mean rpc GDP gr $53-14$ of $2.00 \%$ \\
\hline$\sigma_{g}$ & vol. TFP growth & $2.8 \%$ & Vol rpc GDP gr $53-14$ of $1.95 \%$ \\
\hline$\rho_{g}$ & persistence TFP growth & 0.34 & $\mathrm{AC}(1)$ rpc GDP gr 53-14 \\
\hline$\mu_{\omega}$ & mean idio. depr. shock & $7.5 \%$ & Capital depreciation BEA 53-14 \\
\hline$\sigma_{\omega}$ & vol. idio. depr. shock & $\{0.20,0.45\}$ & Corporate default rates \\
\hline$p_{L L}^{\omega}, p_{H H}^{\omega}$ & transition prob & $0.2,0.99$ & Frequency and duration of credit crises \\
\hline \multicolumn{4}{|c|}{ Production, Population, Labor Income Shares } \\
\hline$\ell^{i}$ & pop. shares $i \in\{S, B, I\}$ & $\{69,28.3,2.7\} \%$ & Population shares SCF 95-13, QCEW 01-15 \\
\hline$\gamma^{i}$ & inc. shares $i \in\{S, B, I\}$ & $\{55,42.4,2.6\} \%$ & Labor inc. shares SCF 95-13, QCEW 01-15 \\
\hline$\alpha$ & labor share in production & 0.66 & Standard value (Kydland-Prescott) \\
\hline$\psi$ & marginal adjustment cost & 1 & Vol. investment-to-GDP ratio $53-14$ of $1.23 \%$ \\
\hline \multicolumn{4}{|c|}{ Corporate loans } \\
\hline$\delta$ & average life loan pool & 0.937 & Duration Fcn. (Appendix B) \\
\hline$\theta$ & principal fraction & 0.582 & Duration Fcn. (Appendix B) \\
\hline$\phi$ & maximum LTV ratio & 0.50 & FoF nonfinancial sectors $85-14$ \\
\hline$\zeta$ & DWL of bankruptcy & $\{0.2,0.5\}$ & Corporate loan and bond severities $81-15$ \\
\hline \multicolumn{4}{|c|}{ Preferences } \\
\hline$\beta^{S}=\beta^{I}$ & time discount factor $\mathrm{S}, \mathrm{I}$ & 0.985 & Mean risk-free rate $85-14$ \\
\hline$\beta^{B}$ & time discount factor $\mathrm{B}$ & 0.86 & Mean investment-to-GDP ratio $53-14$ of $13.3 \%$ \\
\hline$\sigma^{S}$ & risk aversion $\mathrm{S}$ & 20 & Vol. risk-free rate $85-14$ \\
\hline$\sigma^{B}$ & risk aversion $\mathrm{B}$ & 2 & Vol. of log corp. debt/GDP $85-14$ of $4.4 \%$ \\
\hline$\sigma^{I}$ & risk aversion I & 1 & Financial leverage $85-14$ of $95.6 \%$ \\
\hline$\nu$ & intertemp. elasticity of subst. & 1 & \\
\hline \multicolumn{4}{|c|}{ Government Policy } \\
\hline$\tau$ & personal income tax rate & $26.21 \%$ & BEA govt pers tax rev to GDP $53-14$ of $17.30 \%$ \\
\hline$\tau_{\Pi}$ & corporate income tax rate & $16.24 \%$ & BEA govt corp. tax rev to GDP $53-14$ of $3.41 \%$ \\
\hline$G^{o}$ & exogenous govt spending & $17.58 \%$ & BEA govt. discr. spending to GDP 53-14 \\
\hline$G^{T}$ & govt transfers to agents & $3.19 \%$ & BEA govt. net transfers to GDP $53-14$ \\
\hline$\kappa$ & deposit insurance fee & 0 & Deposit insurance fee \\
\hline$\xi$ & margin & 0.95 & Basel II reg. capital charge (C\&I loans) \\
\hline$\sigma_{\rho}$ & bank bankruptcy & $5 \%$ & Technical assumption \\
\hline
\end{tabular}


Depreciation In each period, firms face idiosyncratic stochastic capital depreciation shocks $\omega_{i, t}$, which are drawn from a Gamma distribution characterized by shape and a scale parameters $\left(\chi_{t, 0}, \chi_{t, 1}\right) . F_{\omega}\left(\cdot ; \chi_{t, 0}, \chi_{t, 1}\right)$ is the corresponding CDF. We choose $\left\{\chi_{t, 0}, \chi_{t, 1}\right\}$ to keep the mean $\mu_{\omega}$ constant at 0.925 , implying annual depreciation of capital of $7.5 \%$. This is the observed depreciation rate in the 1953-2014 BEA fixed asset data, calculated as the average ratio of depreciation of total private nonresidential fixed assets to the net stock of total private nonresidential fixed assets, both measured at current cost.

Credit crises We let the cross-sectional standard deviation $\sigma_{t, \omega}$ follow a 2-state Markov chain. Fluctuations in $\sigma_{t, \omega}$ govern aggregate corporate credit risk and represent the second source of exogenous aggregate risk. We refer to states with the high value for $\sigma_{t, \omega}$ as credit crises. We set the two values $\left(\sigma_{H, \omega}, \sigma_{L, \omega}\right)=(0.25,0.40)$. We also allow the deadweight losses of default to vary across the two aggregate credit risk states $\left(\zeta_{H}, \zeta_{L}\right)=(0.2,0.5)$. Together, these four parameters are important drivers of the default rate and the severity rate (loss given default rate) in normal times and in credit crises. Our baseline model generates an average default rate of $4.0 \%$, an average severity of $40 \%$, and thus an average loss rate of $1.9 \%$. We look at two sources of data: corporate loans and corporate bonds. From the Flow of Funds, we obtain delinquency and charge-off rates on Commercial and Industrial loans and Commercial Real Estate loans by U.S. Commercial Banks for the period 1991-2015. The average delinquency rate is $3.1 \%$ and the average loss rate is $0.7 \%$. Default rates and severity rates are much higher in the recessions of 1991, 2001, and 2007-09. The second source of data is Standard \& Poors' default rates on publicly-rated corporate bonds for 1981-2014. The average default rate is $1.5 \%$; $0.1 \%$ on investment-grade bonds and $4.1 \%$ on high-yield bonds. The average severity rate on S\&P and Moody's rated defaults between 1985 and 2004 is 44\%. Our average default rate is between that on all commercial bank loans and that on high yield corporate bonds. We match observed severity rates.

To pin down the transition probabilities of the 2-state Markov chain for $\sigma_{t, \omega}$, we assume that when the aggregate income growth rate in the current period is high $(g$ is in one of the top three income states), there is a zero chance of transitioning from the $\sigma_{L, \omega}$ to the $\sigma_{H, \omega}$ state and a $100 \%$ chance of transitioning from the $\sigma_{H, \omega}$ to the $\sigma_{L, \omega}$ state. Conditional on low growth $(g$ is 
in one of the bottom two income states) we calibrate the two transition probability parameters (rows have to sum to 1 ), $p_{L L}^{\omega}$ and $p_{H H}^{\omega}$, to match the frequency and length of credit crises. Based on the historical frequency of financial crises in Reinhart and Rogoff (2009), we target a $10 \%$ probability of a credit crisis. Conditional on a crisis, we set the expected length to 2 years, based on evidence in Reinhart and Rogoff. Thus, the model implies that not all recessions are credit crises, but all credit crises are recessions.

Production We set the marginal adjustment cost parameter $\psi=1$ in order to match the observed volatility of the ratio of investment to GDP of $1.23 \%$. We set the parameter $\alpha$ which governs the overall labor income share in the Cobb-Douglas production function equal to its standard value of 0.66 .

Population and wealth shares To pin down the population shares of our three different types of households we turn to the Survey of Consumer Finance (SCF).$^{13}$ We define savers as those households who have a low share of their (non-housing) wealth in risky assets. In particular, we compute for each household in the survey the share of assets, net of all real estate, held in stocks or private business equity, considering both direct and indirect holdings of stock. Using this definition of the risky asset share, we then calculate the fraction of households whose share is less than one percent. This amounts to $69 \%$ of SCF households. The remaining $31 \%$ of households have a large risky asset share. We split them into $28.3 \%$ borrowers-entrepreneurs and $2.7 \%$ financial intermediaries based on the share of employees that work in the financial sector, defined as "Securities, Investments" and "Credit Intermediation" from the Quarterly Census of Employment and Wages, averaged over the longest available sample 2001-2015. From the same QCEW data, we obtain the wage share for the intermediaries of $2.6 \%$. The labor income share of savers in the SCF is $55 \%$. The income share of the borrower-entrepreneurs must then be the remaining $42.4 \%$. The population shares are used for the welfare calculations while the income shares determine the Cobb-Douglas parameters $\gamma_{I}, \gamma_{B}$, and $\gamma_{S}$. By virtue of the calibration, the model matches basic aspects of the observed income distribution.

The intermediaries' profits are endogenous and we can compare the total income of the financial intermediaries relative to GDP to the data. Philippon (2015) reports that finance

\footnotetext{
${ }^{13}$ We use all survey waves from 1995 until 2013 and average across them.
} 
produces $5.4 \%$ of value-added over the 1953-2009 period.

Corporate Loans In our model, a corporate loan is a geometric bond. The issuer of one bond (firm) at time $t$ promises to pay the holder (intermediary) 1 at time $t+1, \delta$ at time $t+2$, $\delta^{2}$ at time $t+3$, and so on. Given that the present value of all payments $(1 /(1-\delta))$ can be thought of as the sum of a principal (share $\theta$ ) and an interest component (share $1-\theta$ ), we define the book value of the debt as $\theta /(1-\delta)$. This book value of debt is used in the firm's collateral constraint. We set $\delta=0.937$ and $\theta=0.582$ to match the observed duration of corporate bonds. Appendix B.1 contains the details. The model's corporate loans have a duration of 7 years on average.

Borrowers can obtain a loan with principal value up to a fraction $\phi$ of the market value of their house. We set the LTV ratio parameter $\phi=0.5$ to match non-financial sector leverage. In the Flow of Funds data, the average ratio of loans and debt securities of the nonfinancial corporate and nonfinancial noncorporate businesses to their non-financial assets is $37 \% .{ }^{14}$

Preference parameters Preference parameters are harder to pin down directly by data since they affect many equilibrium quantities and prices simultaneously. For simplicity, we assume all three agents have unit elasticity of intertemporal substitution $\nu$, a common value in the asset pricing literature. The subjective time discount factor and risk aversion coefficients are agentspecific. Risk aversion and the time discount factor of the saver disproportionately affect the short-term interest rate and its volatility. We set $\beta^{S}=\beta^{I}=0.985$ to match the low observed mean real rate of interest. Risk aversion of the saver $\sigma_{S}$ is chosen to match the volatility of the real interest rate. In the data, the mean real interest rate is $1.2 \%$ with a volatility of $2.0 \%$ over the period $1985-2014 .^{15}$

We set $\beta_{B}=0.86$ to instill a strong borrowing motive in the borrower-entrepreneur. This parameter is important for matching the economy's investment-to-output ratio. We target the observed $13.3 \%$ ratio of total private nonresidential fixed investment to GDP. We choose risk

\footnotetext{
${ }^{14}$ For the Flow of Funds leverage data, we use the post-1987 sample. Only in this sample does nonfinancial leverage become stationary.

${ }^{15}$ To calculate the real rate, we take the nominal one year constant maturity Treasury yield (FRED) and subtract expected inflation over the next 12 months from the Survey of professional Forecasters. The mean interest rate is sensitive to the sample period. Over the period 1990-2014, the mean is $0.7 \%$ and over the period 1998-2014, it is only $0.2 \%$.
} 
aversion of the borrower $\left(\sigma_{B}=2\right)$ to target the volatility of changes in the Flow of Funds corporate debt to GDP ratio, which is $4.38 \%$.

Finally, we set risk aversion of the intermediaries equal to $\sigma_{I}=1$ in order to match the leverage of the financial sector. The average ratio of total debt to total assets for 1985-2014 is $95.6 \% .^{16}$

Government parameters We set discretionary government spending $\left(G^{o}\right)$ equal to $17.58 \%$ of GDP, as in the 1953-2014 NIPA data. Transfer spending, which flows back to the households, averages $3.19 \%$ as in the data. We make transfer spending countercyclical: $G_{t}^{T}=G^{T}\left(\bar{g} / g_{t}\right)^{4.5}$ so as to capture the observed $-36 \%$ correlation between transfer spending/GDP and real per capita GDP growth. ${ }^{17}$

We set the labor income tax rate parameter $\tau$ to match the observed income tax revenue to GDP of $17.30 \% .{ }^{18}$ We set the corporate income tax rate to match observed corporate tax revenues of $3.41 \%$ of GDP. Given the tax shield of debt for nonfinancial and financial corporations, we must set the corporate tax rate to $16.2 \%$ to hit the corporate tax revenue target.

The third source of government spending is interest service on the debt, which is endogenous, since both quantity and price of government debt are determined in equilibrium. In the data,

\footnotetext{
${ }^{16}$ Specifically, we include U.S. Chartered Commercial Banks and Savings Institutions, Foreign Banking offices in U.S., Bank Holding Companies, Banks in U.S. Affiliated Areas, Credit Unions, Finance Companies, Security Brokers and Dealers, Funding Corporations, Life and Property-Casualty Insurance Companies, GSEs, Agencyand GSE-backed Mortgage pools, Issuers of ABS, and REITs. Krishnamurthy and Vissing-Jorgensen (2015) identify a group of financial institutions as net suppliers of safe, liquid assets. This group is the same as ours except that we add insurance companies and take out money market mutual funds, since we are interested in leveraged financial firms. For comparison, leverage for the Krisnamurthy and Vissing-Jorgensen institutions is 90.7\% for the 1985-2014 sample. The group of excluded, non-levered financial institutions are Money Market Mutual Funds, other Mutual Funds, Closed-end funds and ETFs, and State, Local, Federal, and Private Pension Funds. Total financial sector leverage, including these non-levered institutions, is $60.6 \%$.

${ }^{17} 4.5$ is the coefficient in a regression of detrended transfer spending growth on GDP growth times 0.7 which is our simulation sensitivity of GDP growth to TFP growth.

${ }^{18}$ We define income tax revenue as current personal tax receipts (line 3) plus current taxes on production and imports (line 4) minus the net subsidies to government sponsored enterprises (line 30 minus line 19) minus the net government spending to the rest of the world (line $25+$ line $26+$ line 29 - line 6 - line 9 - line 18). Our logic for adding the last three items to personal tax receipts is as follows. Taxes on production and export mostly consist of federal excise and state and local sales taxes, which are mostly paid by consumers. Net government spending on GSEs consists mostly of housing subsidies received by households which can be treated equivalently as lowering the taxes that households pay. Finally, in the data, some of the domestic GDP is sent abroad in the form of net government expenditures to the rest of the world rather than being consumed domestically. Since the model has no foreigners, we reduce personal taxes for this amount, essentially rebating this lost consumption back to domestic agents.
} 
net interest payments on government debt average to $2.98 \%$ of GDP. ${ }^{19}$ This number is close to the observed average budget deficit of $3.04 \%$ of GDP. We do not aim to match this number since the U.S. government cannot run a 3\% deficit in perpetuity. In our calibration the personal and corporate tax revenue of $20.71 \%$ of GDP is close to the discretionary and transfer spending of $20.77 \%$ of GDP. For these parameters, government debt to GDP will hover around zero and result in a government net interest expense close to 0 as well. Government debt to GDP ratio will naturally be stationary, as one would want in a steady state. ${ }^{20}$

We can interpret the risk-taker borrowing constraint parameters, $\xi$, as a regulatory capital constraint set by the government. Under Basel II and III, corporate loans and bonds have a risk weight that depends on their credit quality. For a $40 \%$ loss given default, the risk weight on C\&I loans with 2.5 year maturity ranges from $13 \%$ for AAA, $54 \%$ for BBB-, $125 \%$ for B+, to $325 \%$ for CCC. A blended regulatory capital requirement of 5\% (8\% times a blended risk weight of $62.5 \%$ ) seems appropriate. This implies that $\xi=0.95$.

We set the deposit insurance fee parameter $\kappa=0$ to reflect the fact that banks were not required to pay any deposit insurance fees between 1997 and $2006 .^{21}$

Utility cost of risk-taker bankruptcy The model features a random utility penalty that intermediaries suffer when they default. Because random default is mostly a technical assumption, it is sufficient to have a small penalty at least some of the time. We assume $\rho_{t}$ is normally distributed with a mean of $\mu_{\rho}=1$, i.e., a zero utility penalty on average, and a small standard deviation of $\sigma_{\rho}=0.05$. The mean size of the penalty affects the frequency of financial sector defaults (and government bailouts). The lower $\mu_{\rho}$, the lower the resistance to declare bankruptcy, and the higher the frequency of bank defaults. The standard deviation affects the correlation between negative intermediary wealth and bank defaults. Given those parameters, the fre-

\footnotetext{
${ }^{19}$ Net interest expenses are interest payments to persons and businesses (line 28) minus income receipts on asses (line 10).

${ }^{20}$ In our numerical work, we guarantee the stationarity of the ratio of government debt to GDP by gradually decreasing personal tax rates $\tau_{t}$ when debt-to-GDP falls below $\underline{b}^{G}=0$ and by gradually increasing personal tax rates when debt-to-GDP exceed $\overline{b^{G}}=1.2$. Specifically, taxes are gradually and smoothly lowered with a convex function until they hit zero at debt to GDP of $-30 \%$. Tax rates are gradually and convexly increased until they hit $40 \%$ at a debt-to-GDP ratio of $160 \%$. Our simulations never reach the $-30 \%$ and $+160 \%$ debt $/$ GDP states. These profligacy and austerity tax policies do not affect the amount of resources that are available for private consumption in the economy.

${ }^{21}$ FDIC premia were raised after the crisis. Well capitalized banks currently pay 2.5 cents per $\$ 100$ insured.
} 
quency of financial crises (government bailouts of intermediaries) depends on the frequency of credit crises, and the endogenous choices (asset and liability choice) of the intermediaries.

\section{Results}

We present results from a long simulation of the model (10,000 years). For all variables of interest, we report averages and standard deviations over time, as well as averages conditional on being in a good state (positive GDP growth and no credit crisis, i.e. $\sigma_{\omega, L}$ ), non-financial recession (negative GDP growth, $\sigma_{\omega, L}$ ), and financial recession (negative GDP growth and $\sigma_{\omega, H}$ ). We start by presenting standard macroeconomic moments, before turning to the financial sector.

\subsection{Macro Quantities}

The model matches several aggregate quantity moments by virtue of the calibration. These include the mean investment-to-output ratio (14.1\% vs. $13.3 \%$ in data), its volatility (1.05\% vs. $1.23 \%$ in data), the mean capital-to-output ratio (1.49 vs. 1.27 in the data), mean government consumption-to-output (17.48\% vs. $17.58 \%$ in data), mean transfer spending-to-output $(3.24 \%$ vs. $3.19 \%$ in data), personal income tax revenue-to-output (17.51\% vs. $17.30 \%$ in data). The model also closely matches the mean, standard deviation, and autocorrelation of changes in log real per capita GDP. GDP growth is endogenous in the model, but we chose the moments of the productivity process to match these moments, given all other parameters. The model generates amplification in the sense that GDP growth has higher persistence (36\% autocorrelation vs. $34 \%$ in data) than TFP growth (24\%).

Table 2 reports the unconditional moments of log changes in (real per capita) GDP and its four main components for the data (Panel A) and the model (Panel B). The model is able to generate investment growth which is substantially more volatile than GDP growth. The model overstates the volatility of business investment (17.2\% vs. $6.1 \%$ in the data). It also somewhat overstates the volatility of aggregate consumption growth (2.9\% vs. $1.8 \%$ in data). The reason that both are overstated is that investment-to-output and consumption-to-output are even more negatively correlated in the model $(-79 \%)$ than in data $(-46 \%)$. 
Table 2: Unconditional Macroeconomic Quantity Moments

\begin{tabular}{|c|c|c|c|c|}
\hline & mean & stdev & corr. w. $\Delta y$ & $\mathrm{AC}$ \\
\hline & \multicolumn{4}{|c|}{ Data } \\
\hline$\Delta y$ & $2.00 \%$ & $1.94 \%$ & 1.000 & 0.339 \\
\hline$\Delta x$ & $3.25 \%$ & $6.14 \%$ & 0.784 & 0.242 \\
\hline$\Delta c$ & $2.14 \%$ & $1.78 \%$ & 0.873 & 0.321 \\
\hline$\Delta g$ & $0.56 \%$ & $2.53 \%$ & 0.292 & 0.460 \\
\hline $\mathrm{X} / \mathrm{K}$ & $10.51 \%$ & $0.89 \%$ & 0.442 & 0.822 \\
\hline \multirow[t]{2}{*}{$\mathrm{X} / \mathrm{Y}$} & $13.29 \%$ & $1.23 \%$ & 0.187 & 0.867 \\
\hline & \multicolumn{4}{|c|}{ Model } \\
\hline$\Delta y$ & $1.94 \%$ & $1.97 \%$ & 1.000 & 0.358 \\
\hline$\Delta x$ & $1.94 \%$ & $17.18 \%$ & 0.257 & -0.549 \\
\hline$\Delta c$ & $1.94 \%$ & $2.91 \%$ & 0.735 & -0.271 \\
\hline$\Delta g$ & $1.94 \%$ & $2.84 \%$ & 0.349 & 0.242 \\
\hline $\mathrm{X} / \mathrm{K}$ & $9.46 \%$ & $1.29 \%$ & 0.617 & 0.443 \\
\hline $\mathrm{X} / \mathrm{Y}$ & $14.49 \%$ & $1.55 \%$ & 0.529 & 0.171 \\
\hline
\end{tabular}

To understand the workings of the model, it is useful to separate out periods in which the economy is in expansion, from those where it is in a non-financial recession, from those where it is in a financial recession. Financial recessions are states where both TFP growth is below average and there is a credit crisis ( $\sigma_{\omega}$ is high). We recall that every credit crisis is also a period of low TFP growth. GDP growth between period $t-1$ and $t$ is $3.6 \%$ when period $t$ is an expansion, $-0.26 \%$ when $t$ is a non-financial recession, and $-0.60 \%$ when it is a financial recession. As in the data, financial recessions are worse than non-financial recessions in terms of economic growth. The differences in investment growth are even larger. It is $6.4 \%$ in expansions, $-3.7 \%$ in non-financial recessions, and $-16.2 \%$ in financial recessions. Aggregate consumption growth is only slightly negative in non-financial (-0.34\%) recessions and essentially zero (-0.04\%) in financial recessions, suggesting that the agents in the model do a good job sharing risk across dates and states. We come back to this below.

\subsection{Financial Variables}

Next, we turn to the various balance sheet variables, reported in Table 3.

Firms The first two rows of the borrower panel show the market value of assets $\left(p_{t} K_{t}^{B}\right)$ and the market value of liabilities of the non-financial corporate sector $\left(q_{t}^{m} A_{t}^{B}\right)$, both scaled by GDP 
and measured at the beginning of the period. The difference between these two is the market value of firm equity scaled by GDP. The ratio of the two is the mark-to-market leverage ratio, i.e., the ratio of the market value of debt to the market value of assets (row 4). Entrepreneurs own about half of their firms in the form of corporate equity, on average.

The market leverage ratio is about the same in expansions as in non-financial recessions. Non-financial recessions see an increase in both the market value of assets and liabilities relative to expansions, keeping the market value of equity unchanged. The increase in the market value of capital is entirely accounted for by a rise in the capital-to-output ratio $K_{t}^{B} / Y_{t}$ because there is a modest decline in the price of capital $p$ (row 15). Naturally, capital does not fall as much as output in (non-financial) recessions. The market value of debt rises because firms increase the quantity of debt relative to GDP, $A_{t}^{B} / Y_{t}$ (row 3). The price of corporate debt $q_{t}^{m}$ does not change much between expansions and non-financial recessions. Indeed, row 17 shows that the interest rate on corporate loans changes little.

Financial recessions affect corporations quite differently. First off, the drop in the price of capital is much larger in financial recessions. But the capital to output ratio increases a lot more as well so that the market value of capital is higher in financial recessions than in expansions. The main difference is that the price of debt is much lower in financial recessions, or equivalently the interest rate on corporate debt is much higher. Corporate leverage in market terms falls. The market value of corporate equity rises. Book debt actually increases (row 3), at least relative to a depressed GDP.

The borrower-entrepreneurs' book leverage is $46 \%$ on average, measured as book value of debt to market value of assets (row 5). This compares to $37 \%$ for non-financial firms in the data. The model matches the observed volatility of the corporate debt-to-GDP ratio. In the model, borrowers are always up against their leverage constraint. The reasons are that they are sufficiently impatient and the tax shield is valuable. In financial recessions, the market value of firm collateral falls and borrowing constraints tighten. This reduces the firm's debt capacity and its actual leverage, given that the constraint binds.

Borrowers default when the book value of their debt falls below the market value of their (collateral) assets. The model generates average corporate default and loss rates of $2.2 \%$ (row 6 ) and $1.0 \%$ points (row 8), respectively, implying an average loss-given-default rate of $37.1 \%$ 
Table 3: Balance Sheet Variables and Prices

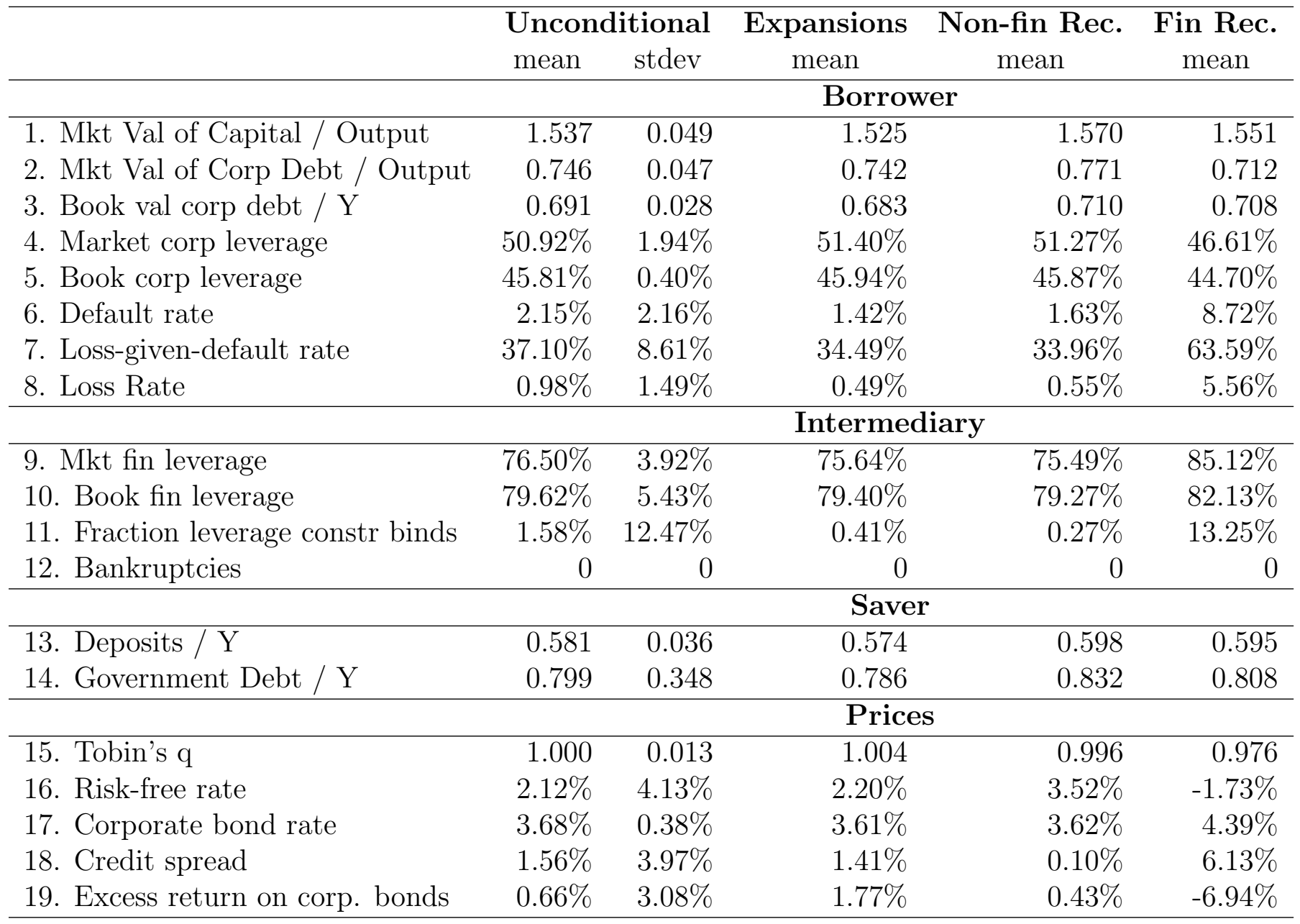

(row 7). All these numbers are in line with the data. Loss rates are a lot higher in financial recessions $(5.6 \%)$ than in non-financial recessions and expansions $(0.5 \%)$. This is the result of both higher default rates and higher losses-given-default. Both are important features of the data.

Intermediaries Intermediary leverage is $77 \%$ in market value and $80 \%$ in book value terms on average in the model. While that is a high leverage ratio, it falls short of the $95.6 \%$ financial leverage target. Intermediaries are highly levered because they enjoy a low cost of funding and earn a high yield on corporate loans: the deposit rate is $2.12 \%$ and the corporate loan rate is $3.68 \%$ on average. Like non-financial corporations, financial intermediaries enjoy an interest expense tax shield which makes leverage more attractive.

Intermediary leverage is lower in non-financial recessions and higher in financial recessions 
than in expansions. In other words, the behavior of financial leverage in opposite that of nonfinancial leverage in financial recessions. The main reason for the rise in financial leverage in financial recessions is that the market value of banks' assets, corporate loans, falls substantially. This occurs because default risk rises which increases corporate bond yields. A lower value of bank assets tightens their regulatory capital constraint. The intermediary leverage constraint binds in $13 \%$ of the financial crises compared to $0.3 \%$ of non-financial recessions. In those periods, intermediaries must reduce deposits to meet their capital requirements in the wake of their credit losses. Still, intermediaries often remain unconstrained in financial recessions and choose not to raise more deposits from households despite the very low deposit rates. This suggests that the expected returns per unit of risk are not conducive to expand their lending activities during financial recessions.

Intermediary net worth, or bank equity, is an important state variable in all intermediarybased models. Intermediary net worth is the difference between the market value of bank assets (row 2) and the book value of deposits (row 13). Intermediary equity to GDP is $16.5 \%$ on average. It shrinks to $11.8 \%$ of GDP in financial recessions, while it rises to $17.3 \%$ in non-financial recessions. The reduction in intermediary net worth itself is larger still since GDP is lowest in financial recessions. The reduction in net worth makes the intermediaries effectively more risk averse, leading them to charge larger risk premia on new lending. At current parameters, banks are well enough capitalized to never go bankrupt (row 12). This is despite the bailout guarantee, or equivalently deposit insurance, which lowers the cost of deposits and provides banks with a risk shifting motive vis-a-vis the government. As risk averse agents, bankers are reluctant to hit low net worth states since they imply low consumption and high marginal utility.

Savers Risk averse savers only hold safe debt: they hold the safe debt supplied by the government and the intermediaries (rows 13 and 14). In the model, these two sources are about $80 \%$ and $60 \%$ of GDP, respectively. ${ }^{22}$ Because of a strongly countercyclical primary deficit (to GDP ratio) and only mildly procyclical interest expenses, the government must raise more resources from savers in recessions. In equilibrium, the total amount of safe debt from deposits

\footnotetext{
${ }^{22}$ At the benchmark parameters, the government-to-GDP ratio is stationary and lives on the interior of the state space.
} 
and governments is nearly identical in financial and non-financial recessions. But its price is much higher in financial recessions. Put differently, both the demand and the supply curve for safe debt shift up in financial versus non-financial recessions, causing a higher bond price at roughly the same quantity of debt. The conditional variance of consumption growth is higher in financial recessions for savers, stimulating their precautionary motives and demand for safe assets. Because intermediaries have lower net worth and are more constrained, they are only willing to provide the same amount of deposits at a lower deposit rate.

Prices Real interest rates on safe debt are $2.1 \%$ on average and have a volatility of $4.1 \%$ (row 16). In non-financial recessions, which are high marginal utility states for the saver, banks have to raise risk-free rates to attract additional deposits. Faced with strong corporate collateral values (row 15) and low default rates, banks view the corporate lending environment as favorable. In contrast, financial recessions see large declines in collateral values, negative (excess) returns on bank assets (row 19), high corporate credit spreads (row 18), and very low real interest rates (row 16). All of these are important features of real-life financial crises.

\subsection{Consumption and Welfare}

Table 4 reports the moments of consumption for each agents, as well as each agent's value function, and aggregate welfare. By virtue of being the largest groups of agents, borrowers and depositors have the highest consumption shares (relative to GDP). More interesting is consumption growth in the second panel. It reveals that the intermediary has by far the most volatile consumption growth, followed by the saver, and the borrower. All agents have the same elasticity of intertemporal substitution, but the saver has the highest risk aversion, followed by the borrower, and the intermediary who has the lowest risk aversion. Thus, the borrower has a relatively low consumption growth volatility and the saver a relatively high one, given their risk aversions. The reason is that the borrower is able to smooth consumption much better than the saver. The saver is stuck absorbing fluctuating amounts of safe assets, expanding saving and cutting consumption in the worst possible states of nature. As a case in point, consumption growth for the saver is negative in financial crises but positive for the borrower. Due to their low risk aversion, intermediaries' role in the economy is to help the saver and borrower share risk. 
Table 4: Consumption and Welfare

\begin{tabular}{|c|c|c|c|c|c|}
\hline & $\begin{array}{l}\text { Uncon } \\
\text { mean }\end{array}$ & $\begin{array}{l}\text { itional } \\
\text { stdev }\end{array}$ & $\begin{array}{c}\text { Exp } \\
\text { mean }\end{array}$ & $\begin{array}{c}\text { Non-fin Rec } \\
\text { mean }\end{array}$ & $\begin{array}{c}\text { Fin Rec } \\
\text { mean }\end{array}$ \\
\hline & \multicolumn{5}{|c|}{ Consumption to Output } \\
\hline Consumption, B & 0.343 & 0.006 & 0.342 & 0.343 & 0.356 \\
\hline Consumption, I & 0.016 & 0.002 & 0.017 & 0.017 & 0.011 \\
\hline \multirow[t]{2}{*}{ Consumption, S } & 0.315 & 0.010 & 0.316 & 0.314 & 0.314 \\
\hline & \multicolumn{5}{|c|}{ Consumption growth } \\
\hline Consumption, B & $1.94 \%$ & $1.98 \%$ & $2.63 \%$ & $-0.12 \%$ & $1.73 \%$ \\
\hline Consumption, I & $1.94 \%$ & $13.37 \%$ & $6.58 \%$ & $-0.31 \%$ & $-26.71 \%$ \\
\hline \multirow[t]{2}{*}{ Consumption, S } & $1.94 \%$ & $4.87 \%$ & $3.11 \%$ & $-0.58 \%$ & $-0.75 \%$ \\
\hline & \multicolumn{5}{|c|}{ Welfare } \\
\hline DWL / Y & 0.004 & 0.006 & 0.002 & 0.002 & 0.024 \\
\hline Value function, B & 0.388 & 0.005 & 0.388 & 0.389 & 0.392 \\
\hline Value function, I & 0.017 & 0.000 & 0.017 & 0.017 & 0.017 \\
\hline Value function, $\mathrm{S}$ & 0.510 & 0.003 & 0.512 & 0.507 & 0.507 \\
\hline \multirow[t]{2}{*}{ Aggregate welfare } & 0.462 & 0.003 & 0.463 & 0.460 & 0.461 \\
\hline & \multicolumn{5}{|c|}{ Marginal utility ratios } \\
\hline $\log (\mathrm{MU} \mathrm{B} / \mathrm{MU} \mathrm{I})$ & 2.294 & 0.168 & 2.339 & 2.326 & 1.890 \\
\hline $\log (\mathrm{MU} \mathrm{B} \mathrm{/} \mathrm{MU} \mathrm{S)}$ & 1.875 & 0.037 & 1.877 & 1.880 & 1.850 \\
\hline $\log (\mathrm{MU} \mathrm{S} / \mathrm{MU} \mathrm{I})$ & 0.420 & 0.157 & 0.463 & 0.446 & 0.040 \\
\hline
\end{tabular}

The intermediary absorbs the credit losses and suffers a $27 \%$ consumption drop in a financial recession. By the same token, the corporate sector gets to shed its defaulted debt and gets to buy back the productive assets at a much lower price. Financial recessions transfer wealth from intermediaries to borrowers.

The third panel reports moments related to aggregate welfare. Deadweight losses from corporate bankruptcies are small relative to GDP (0.4\%), but much larger in financial recessions when the loss rate spikes (2.4\%). This takes away resources from the economy. Aggregate welfare is computed as the population-weighted average of the value functions. It is lower in recessions than in expansions, largely because of the saver's reduction in welfare in recessions. Because the borrowers fare well in financial recessions, welfare is slightly higher in financial than non-financial recessions.

The last panel plots ratios of marginal utilities between pairs of agents. In a complete markets model with agents whose preference parameters differ, these ratios would differ across pairs of agents but all would be constant over time. Our model is an incomplete markets model featuring imperfect risk sharing; the marginal utility ratios display non-trivial volatility. This 
can also be seen by differences in the ratios across expansions and the two types of recessions.

\subsection{Model Dynamics in Financial Crises}

To further understand the dynamics of a credit crisis in the model, we compute impulseresponses. We start off the model in the high-growth state, the highest of five points on the TFP growth grid, and the low $\sigma_{\omega}$ state. All other endogenous variables take their average values in that exogenous state. In the next period the model undergoes a change to the lowest TFP growth grid point. In one instance, the recession is accompanied by a switch to the high $\sigma_{\omega}$ state, a financial recession or credit crisis. In the second instance, the economy remains in the low $\sigma_{\omega}$ state, a non-financial recession. From period 2 onwards, the two exogenous states follow their stochastic laws of motion. Specifically, we simulate 10,000 sample paths of 9 additional years and average across paths. In periods 1 through 10, the endogenous states take on their average value corresponding to the exogenous state that is realized. The exercise allows us to study the transition from a strong economy with a credit boom to a bust with a financial crisis, like we saw in the years before and after 2007-08. It also allows us to understand the differences between financial and non-financial recessions. Figures 1-4 plot the impulse-response functions for the key variables. All quantity variables are normalized to 100 in year 0. Growing quantities are detrended by the constant long-run productivity growth rate.

Figure 1 plots the main aggregate macro-economic time series. They show that GDP, consumption, and investment all fall in the first period of the recession. Government consumption increases by our assumption of countercyclical government spending. What is interesting is that output continues to fall sharply in the year following a financial recession, while it stabilizes

in the year following a non-financial recession. The same is true for consumption. This is not a mechanical effect because the probability of a recession in year 2 is independent of whether or not the economy was in a high credit risk state in year 1. The model generates endogenous amplification. Most of the additional period-2 decline in consumption is due to borrowers who are rebuilding the capital stock - in those period 2 states where TFP recovers - by scaling back consumption. A second interesting finding is that investment takes a much bigger hit in financial than in non-financial recessions in period 1 . After a partial recovery in period 2 , investment drops again in period 3. Even ten years later, investment remains far below the previous peak 
and below the level in a non-financial recession.

Figure 1: Financial vs. Non-financial Recessions: Macro Quantities
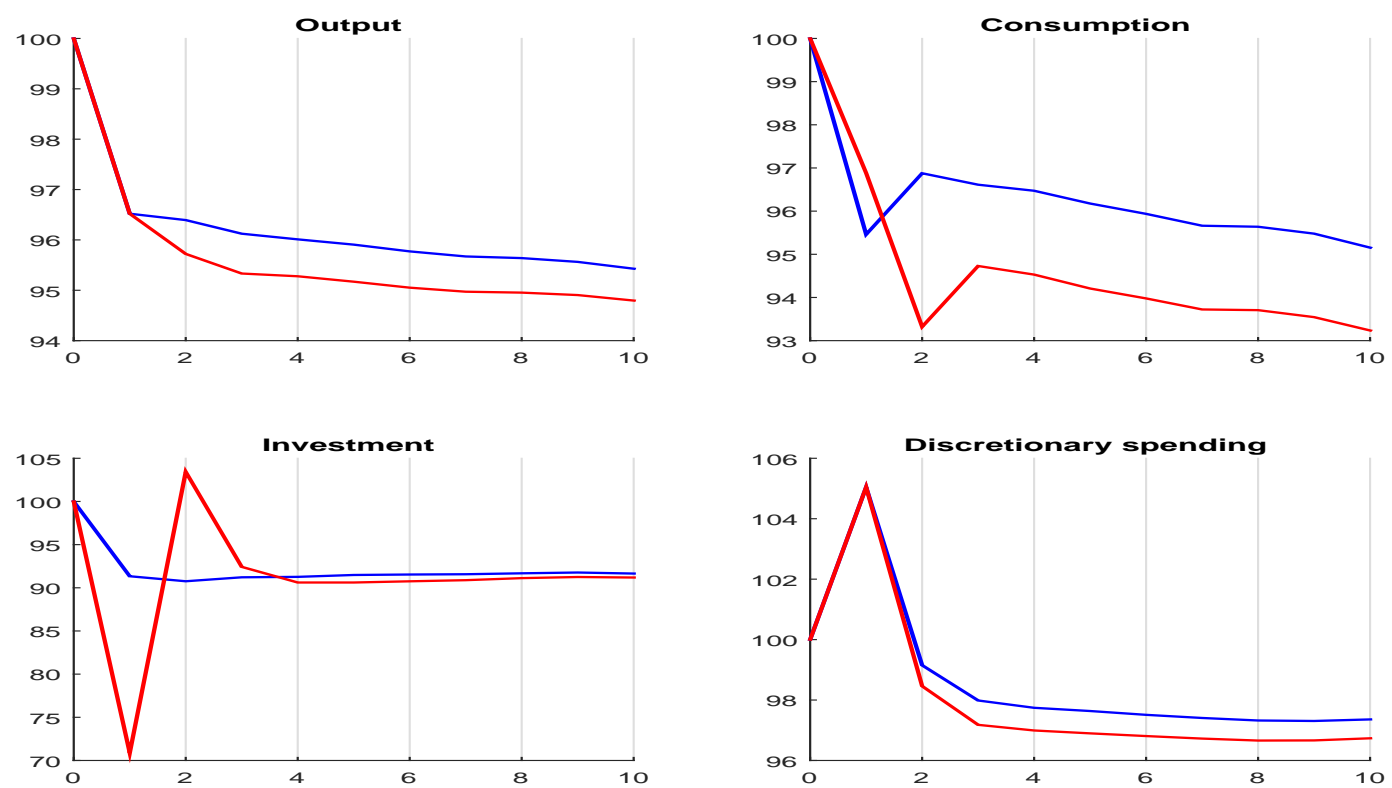

The graphs show the average path of the economy through a recession episode which starts at time 1 . In the previous period, the economy was in a high growth state. The recession is either accompanied by a high dispersion of depreciation (high $\sigma_{\omega}$, financial recession), or low dispersion (low $\sigma_{\omega}$, non-financial recession). From period 2 onwards, the economy evolves according to its regular probability laws. We obtain these via a Monte Carlo simulation of 10,000 paths of periods 2-10, and averaging across these paths. Blue line: non-financial recession Red line: financial recession.

Figure 2 focuses on the assets and liabilities of borrowers and intermediaries. All balance sheet variables are measured at the beginning of the period so that the shock at time 1 only affects them in period 2. That is why all quantity variables are the same in period 1 in financial and non-financial recessions. Market value objects are affected by prices already in period 1 . The first two panels show that firms shrink their balance sheets, both the book value of assets and liabilities, much more in a financial recession than a non-financial recession. In market value terms, firms' debt falls even more due to the decline in the price of debt (bottom left panel). The market value of assets also falls more sharply than the book value because of a decline in the price of assets, but the decline in the market value of assets is smaller than that in the market value of liabilities in financial recessions. Correspondingly, the net worth of the corporate sector increases sharply in financial recessions (top right panel). Entrepreneurs cut consumption thereby increasing the resources inside the firm. One loose interpretation is that 
firms are building reserves, rather than paying out dividends to their owners, in anticipation of future investment needs. The following year, firms indeed resume investment. The bottom panels of Figure 2 show banks' balance sheet items. The market value of banks' assets is in the bottom left, while the deposits in the middle panel are the banks' liabilities (both in market and book value terms). The difference between the two is the banks' net worth, plotted in the right panel. A financial crisis coincides with a sharp drop in bank assets and liabilities. Bank leverage increases sharply in market and book value terms. Bank equity falls by 50 percent in two years. Banks are slow to recapitalize. Even ten years later, their equity is still far from trend. Financial crises redistribute wealth from financial to non-financial firms in the model. By defaulting on their debt and buying back the seized collateral from the banks at fire sale prices, firms are able to recapitalize. Banks absorb the credit losses, resulting in a massive decline in equity.

Figure 2: Financial vs. Non-financial Recessions: Balance Sheet Variables
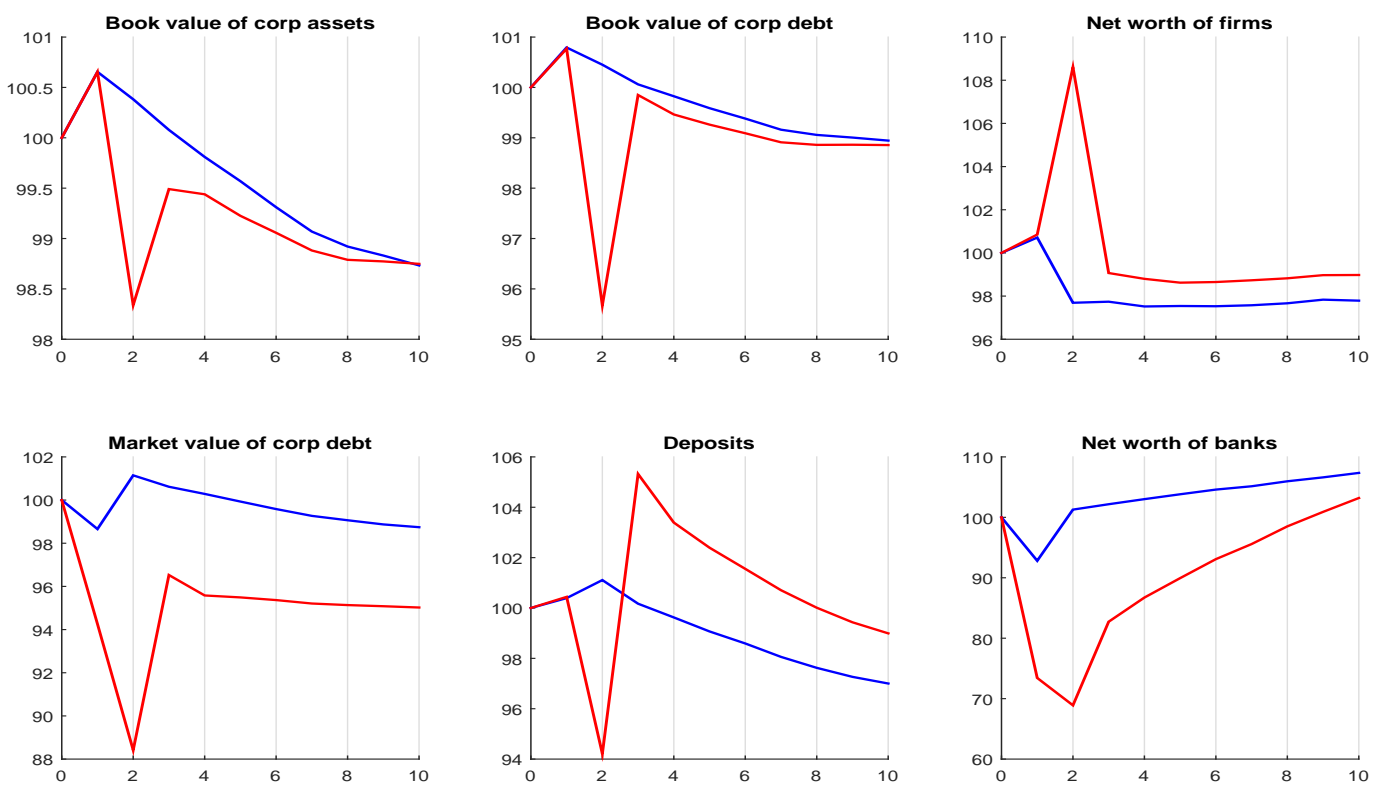

Blue line: non-financial recession Red line: financial recession.

Figure 3 shows the interest rates, the credit spread, and the price of capital. In the first period of a financial recession following a boom, the real risk-free rate turns negative and the credit spread blows out reaching 800 basis points. Financial recessions are periods of high credit risk and credit risk premia, both of which enter in the credit spread. Strong precautionary savings 
motives depress the real rate. In sharp contrast, non-financial recessions see an initial increase in the risk-free rate and a decline in the credit spread. The price of capital falls a lot more in financial recessions. In the year after a financial crisis, the risk-free rate and credit spreads reverse. This occurs because the recession and the credit crisis end with substantial probability in period 2. The loan rate, which is their sum, continues to increase putting further pressure on the value of bank assets. The same reversal can be seen in the price of capital.

Figure 3: Financial vs. Non-financial Recessions: Prices
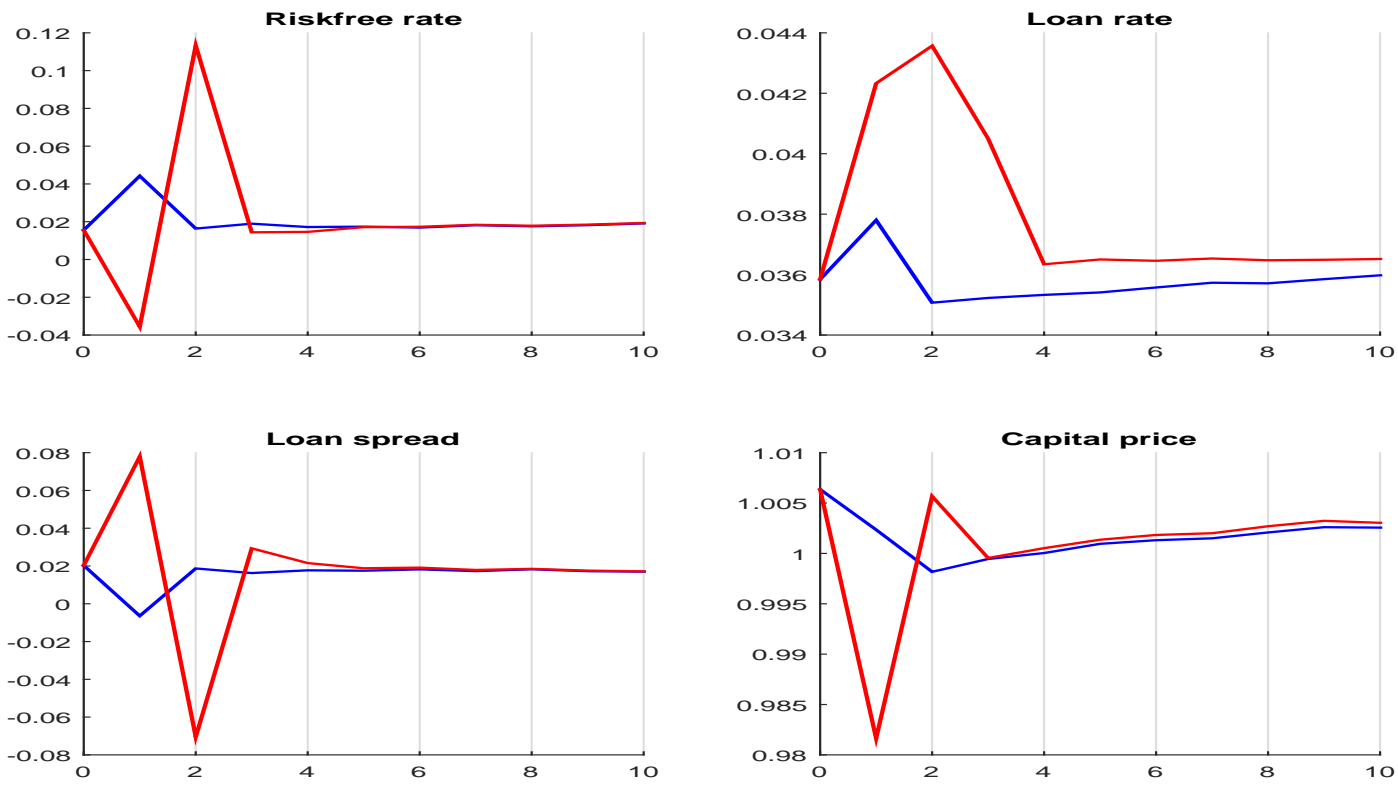

Blue line: non-financial recession Red line: financial recession.

Figure 4 shows the value functions of the three types of agents, and aggregate welfare, their population-weighted average. Two sharp distinctions jump out between non-financial (left panel) and financial recessions. First, savers and especially intermediaries suffer greater welfare losses in a financial recession. In fact, banks gain in a non-financial recession. Second, borrowers suffer much smaller welfare losses in a financial than in a non-financial recession. They are recapitalizing at the expense of the banks, shedding debt in bankruptcy and buying capital at distressed prices, and are able to smooth consumption reasonably well. The net result is that aggregate welfare losses from a recession are about the same for financial and non-financial recessions. They just affect different types of agents very differently. 
Figure 4: Financial vs. Non-financial Recessions: Welfare
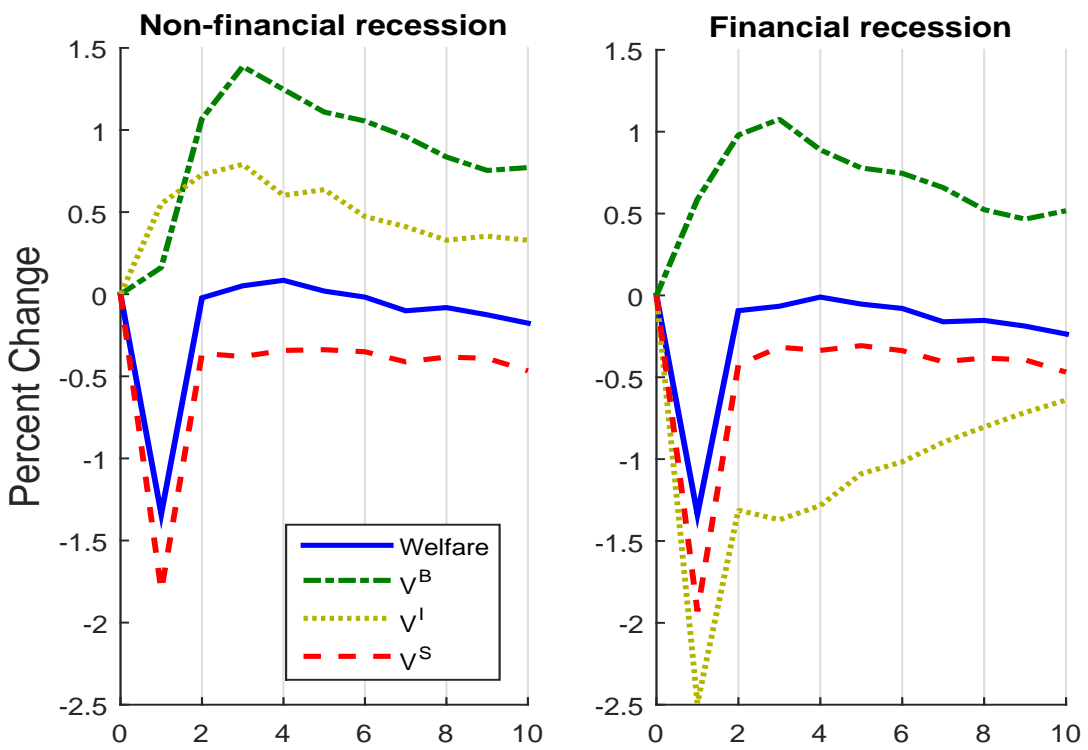

\subsection{Predictive Regressions}

A literature cited in the introduction documents that credit spreads are good predictors of future economic growth. We add to this literature by revisiting this predictive relationship inside a rich structural model that generates endogenous fluctuations in both credit spreads and macroeconomic aggregates.

Table 5 summarizes our predictability results. In Panel A we focus on predicting real per capita GDP growth between period t-1 and t, $\Delta y_{t}$. The first column uses the credit spread at time t-1, $s_{t-1}$, as the predictor. As before, the credit spread is the difference between the yield on long-term defaultable corporate loans and the yield on the short-term safe asset. Since the model is cast at annual frequency, the regression are run based on 10,000 periods of annual simulated data. As is common in the empirical literature, the regression controls for one lag of the dependent variable. T-statistics are reported below the point estimates.

The first column shows that the credit spread forecasts next year's GDP growth with a slope of -0.064 . The $R^{2}$ is $14 \%$. The last row reports that a one standard deviation in the credit spread changes GDP growth by -0.13 standard deviations. In the second column we replace the credit spread at time t- 1 by the change in the credit spread between t- 2 and $\mathrm{t}-1, \Delta s_{t-1}$. If 
the credit spread is persistent, this may be the better specification. The results are identical in terms of economic magnitudes and $R^{2}$. Using annual data from 1929-2013 and the Baa-minusTreasury spread, Lopez-Salido, Stein, and Zakrajsek (2015) report a standardized response of -0.37. While our model generates the correct sign as well as significance, the magnitude of the effect is about $1 / 3$ rd of that found in the data.

In the third column, we additionally control for the lagged change in the short-term bond yield. The $R^{2}$ improves marginally to $15 \%$, and both predictors enter with a negative sign and significantly. The same is true in the data. The economic magnitude of the effect increases to -0.69 standard deviations

Table 5: Predicting Economic Activity with the Credit Spread

\begin{tabular}{lcccccc}
\hline \multicolumn{5}{c}{ Panel A: Predicting $\Delta y_{t}$} \\
& $(1)$ & $(2)$ & $(3)$ & $(4)$ & $(5)$ & $(6)$ \\
\hline$s_{t-1}$ & -0.064 & & & & & \\
$\Delta s_{t-1}$ & -13.73 & & & & & \\
$E E R_{t-1}$ & & -0.037 & -0.198 & & & \\
& & -13.63 & -3.15 & & & \\
$\Delta \hat{s}_{t-1}$ & & & & -0.218 & & \\
& & & & -11.70 & & \\
$\Delta \log (D / Y)_{t-1}$ & & & & & -0.042 & \\
& & & & & -4.92 & \\
$\Delta y_{t-1}$ & 0.373 & 0.373 & 0.367 & 0.335 & 0.359 & 0.336 \\
$\Delta r_{t-1}^{f}$ & 40.01 & 40.01 & 38.23 & 35.29 & 38.47 & 35.17 \\
& & & -0.156 & & & \\
\hline$R^{2}$ & & & -2.57 & & & \\
Stand. effect & -0.128 & -0.127 & -0.688 & -0.111 & -0.046 & -0.059 \\
\hline
\end{tabular}

The credit spread fluctuates because of changes in the expected default rate, the quantity of risk, and because of changes in the price of credit risk. The expected return on corporate loans/bonds in excess of the one-period safe bond rate is a measure of the risk premium. We can directly compute it in the model. Column (4) uses this expected excess return and shows that it, too, forecasts future GDP growth with a negative sign. The $R^{2}$ is the same $14 \%$ as for the credit spread, and the economic effect is -0.111 so that the predictive ability of the credit spread and the risk premium is very similar. Greenwood and Hanson (2013) and Lopez-Salido, 
Stein, and Zakrajsek (2015) provide empirical proxies for the expected excess returns associated with bearing credit risk, interpret them as investor sentiment measures, and show that they predict future economic activity. Our model generates fluctuating "investor sentiment," in that risk premia are time-varying, which predicts economic activity.

In column (5), we repeat the approach of Lopez-Salido, Stein, and Zakrajsek (2015) who instrument changes in the credit spread $\Delta s_{t-1}$ with its projection onto $s_{t-2}$. The instrumented change in credit spread, $\Delta \hat{s}_{t-1}$, continues to predict GDP growth with the right sign, but the economic magnitude is less than half as strong. This indicates that the instrument for the expected excess return is rather weak, at least inside our model.

Finally in column (6) we predict GDP growth between period t-1 and t with the log change in the market value of bank assets to GDP between periods t-2 and t- 1 . This specification is inspired by Mian and Sufi (2016), who show a negative relationship between lagged bank credit growth relative to GDP and future GDP growth. Our model replicates this relationship. The $R^{2}$ is $14 \%$ and the economic impact on GDP growth from a one standard deviation change is -0.06, or about half as large as from the credit spread change.

\subsection{Credit Risk Premium}

The above analysis showed that our model's expected excess return fluctuates over time and has about the same predictive content for GDP growth as the credit spread. An interesting question is which of the state variables in the model are the key drivers of the credit risk premium. In intermediary-based asset pricing models, the net worth share of the intermediary is usually a key state variable. For example, in He and Krishnamurty (2013), when intermediaries represent a small share of total wealth and they require high risk premia to be willing to hold risky assets. Our model features much more complex risk premium dynamics since there are three agents whose wealth shares matter plus government debt plus the capital stock. And the effects of all state variables on the risk premium may be nonlinear. Nevertheless, a linear regression of the credit risk premium on the financial intermediary's wealth share is a natural step to better understand the model's asset pricing implications.

We regress the credit risk premium in the model on the two exogenous state variables, 
measured contemporaneously. They explain $43 \%$ of the risk premium variation. The credit shock $\sigma_{\omega}$ is naturally a stronger driver than TFP growth. When we add financial intermediary and corporate leverage as explanatory variables for the credit risk premium, the $R^{2}$ increases to $64.5 \%$.

Figure 5 shows the histogram of the intermediary wealth share plotted against the credit risk premium. Consistent with the result in He and Krishnamurty (2013), the credit risk premium is high when the financial intermediary's wealth share is low. In a financial crisis, our model generates quantitatively large credit risk premia.

Figure 5: The Credit Risk Premium and the Financial Intermediary Wealth Share

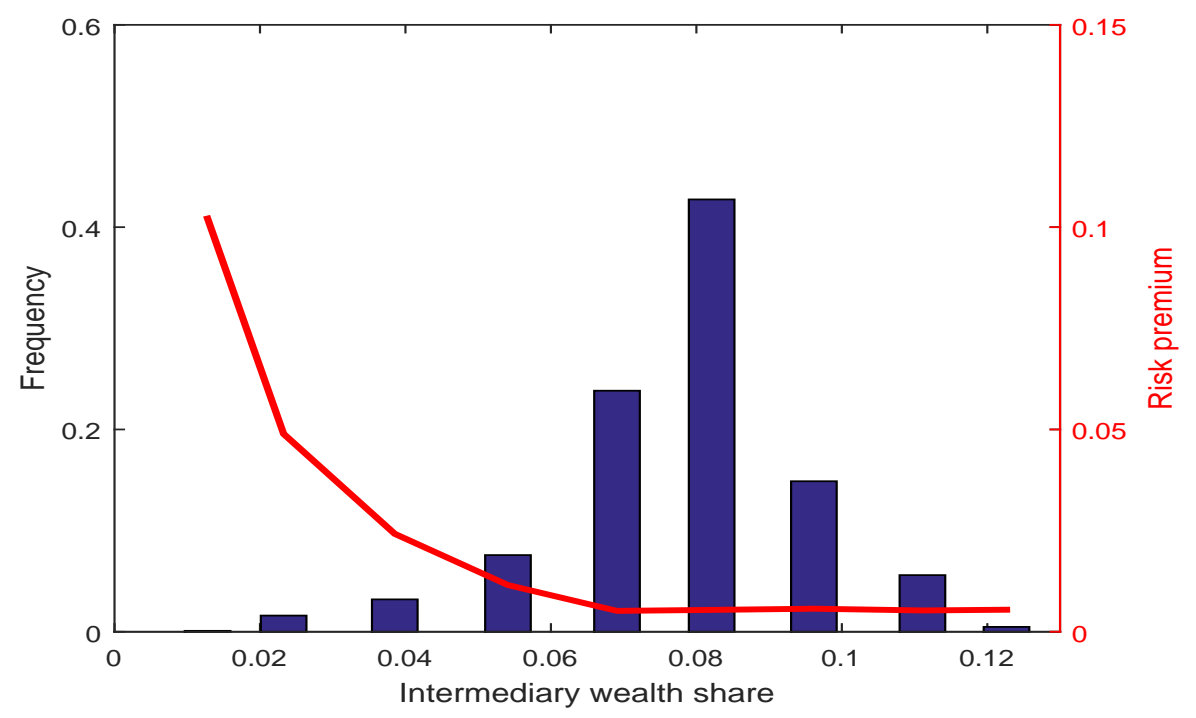

\section{Macro-prudential Policy}

We use our calibrated model to investigate the effects of macro-prudential policy choices. The first exercise we consider is tightening the maximum loan-to-value ratio that applies to corporate borrowers $(\phi)$. It directly constrains the maximum leverage of the non-financial firms. The second experiment increases the regulatory capital weight that enters in banks' Basel constraint $(\xi)$. It directly constrains the maximum leverage of the financial intermediaries. Table 6 presents the results. 
Tightening Firms' LTV Constraint Starting with the tighter LTV limit in column 2, we find that firm book leverage falls by 9 percentage points when $\phi$ is reduced from 0.50 to 0.40 . With lower leverage, default rates drop substantially from $2.15 \%$ in the benchmark to $0.97 \%$. The loss given default rate also falls a bit, resulting in a loss rate that is reduced by $50 \%$. The loss rates drops by 2 percentage points in financial recessions, making them substantially less severe events. The concomitant reduction in deadweight losses from foreclosure $(-56 \%)$ is a first source of welfare gain from this macro-prudential policy.

The second result is that financial intermediaries respond to the improved safety of corporate loans by increasing their leverage. Intermediary leverage rises from $76.5 \%$ to $81.1 \%$. Banks' regulatory capital constraint binds nearly twice as often, especially during financial recessions. Because these financial recessions are less severe, banks regularly want to increase lending to the point where their constraint binds. Banks are smaller. Deposits represent only $51.8 \%$ of GDP compared to $58.1 \%$ in the benchmark model. The reduction in financial intermediation follows from the reduced demand for corporate loans from the firms, induced by macro-prudential policy. The reduction in corporate credit reduces the size of the entire economy: the capital stock and output are smaller than in the benchmark economy by 4.4 and 1.5 percent, respectively. The increased financial stability reduces macro-economic volatility: GDP growth (-1.2\%), consumption growth $(-21.6 \%)$, and investment growth $(-49.6 \%)$ are all less volatile. But it comes at the cost of a smaller economy.

On net, tightening firms' maximum LTV ratio lowers welfare by $0.57 \%$ in consumption equivalence units. The reduction in credit risk in the system benefits the stability of the economy, helping all three agents smooth consumption better. The volatility of all pairwise marginal utility ratios falls. But the smaller size of the economy hurts the mean consumption of all agents. There are interesting distributional implications. Maybe surprisingly, borrowers benefit from having tighter LTV constraints imposed on them. Their value function increases by $1.34 \%$. They consume a larger share of total consumption compared to the benchmark. An important reason for the higher average consumption share is that borrowers pay a lower interest rate on their debt, especially during financial crises.

Savers, who are by far the largest group in the economy, lose from the policy: their value function falls by $1.2 \%$. They earn lower interest rates on their savings. The scarcity of safe 
Table 6: Macroprudential Policy

\begin{tabular}{|c|c|c|c|c|}
\hline & $\begin{array}{c}\text { Benchmark } \\
\text { mean }\end{array}$ & $\begin{array}{c}\text { Lower } \phi \\
\text { mean }\end{array}$ & $\begin{array}{c}\text { Lower } \boldsymbol{\xi} \\
\text { mean }\end{array}$ & $\begin{array}{c}\text { Lower } \phi \text { and } \boldsymbol{\xi} \\
\text { mean }\end{array}$ \\
\hline & \multicolumn{4}{|c|}{ Borrowers } \\
\hline 1. Mkt Val of Capital / Output & 1.537 & 1.492 & 1.532 & 1.486 \\
\hline 2. Mkt Val of Corp Debt / Output & 0.746 & 0.628 & 0.740 & 0.621 \\
\hline 3. Book val corp debt / Y & 0.691 & 0.540 & 0.689 & 0.538 \\
\hline 4. Market corp leverage & $50.92 \%$ & $44.00 \%$ & $50.72 \%$ & $43.72 \%$ \\
\hline 5. Book corp leverage & $45.81 \%$ & $36.94 \%$ & $45.82 \%$ & $36.95 \%$ \\
\hline 6. Default rate & $2.15 \%$ & $0.97 \%$ & $2.10 \%$ & $0.94 \%$ \\
\hline 7. Loss-given-default rate & $37.10 \%$ & $35.85 \%$ & $37.04 \%$ & $35.77 \%$ \\
\hline \multirow[t]{2}{*}{ 8. Loss Rate } & $0.98 \%$ & $0.48 \%$ & $0.96 \%$ & $0.46 \%$ \\
\hline & \multicolumn{4}{|c|}{ Intermediaries } \\
\hline 9. Mkt fin leverage & $76.50 \%$ & $81.14 \%$ & $73.02 \%$ & $76.99 \%$ \\
\hline 10. Book fin leverage & $79.62 \%$ & $84.45 \%$ & $76.03 \%$ & $80.16 \%$ \\
\hline 11. Fraction leverage constr binds & $1.58 \%$ & $2.49 \%$ & $2.24 \%$ & $3.01 \%$ \\
\hline \multirow[t]{2}{*}{ 12. Bankruptcies } & 0 & 0 & 0 & 0 \\
\hline & \multicolumn{4}{|c|}{ Savers } \\
\hline 13. Deposits / Y & 0.581 & 0.518 & 0.550 & 0.486 \\
\hline \multirow[t]{2}{*}{ 14. Government Debt / Y } & 0.799 & 0.390 & 0.814 & 0.409 \\
\hline & \multicolumn{4}{|c|}{ Prices } \\
\hline 15. Tobin's q & 1.000 & 1.000 & 1.000 & 1.000 \\
\hline 16. Risk-free rate & $2.12 \%$ & $1.87 \%$ & $2.16 \%$ & $1.91 \%$ \\
\hline 17. Corporate bond rate & $3.68 \%$ & $2.97 \%$ & $3.73 \%$ & $3.03 \%$ \\
\hline 18. Credit spread & $1.56 \%$ & $1.10 \%$ & $1.57 \%$ & $1.12 \%$ \\
\hline \multirow[t]{2}{*}{ 19. Excess return on corp. bonds } & $0.66 \%$ & $0.66 \%$ & $0.69 \%$ & $0.70 \%$ \\
\hline & \multicolumn{4}{|c|}{ Welfare } \\
\hline 20. DWL / Y & 0.004 & $-56.08 \%$ & $-2.65 \%$ & $-57.96 \%$ \\
\hline 21. Value function, B & 0.388 & $+1.34 \%$ & $-0.19 \%$ & $+1.11 \%$ \\
\hline 22. Value function, I & 0.017 & $-3.34 \%$ & $+1.28 \%$ & $-2.02 \%$ \\
\hline 23. Value function, $\mathrm{S}$ & 0.510 & $-1.16 \%$ & $-0.08 \%$ & $-1.27 \%$ \\
\hline 24. Aggregate welfare & 0.462 & $-0.57 \%$ & $-0.10 \%$ & $-0.70 \%$ \\
\hline
\end{tabular}

debt allows banks and the government to pay a lower safe interest rate.

Finally, the banks are the biggest losers from this policy because (i) their operations shrink in size, and (ii) the difference between the yield on their assets and liabilities, the credit spread, shrinks. These effects dominate the improved risk sharing benefit because intermediaries are not all that risk averse. 
Tightening Banks' LTV Constraint The next experiment we investigate is a regulatory increase in bank equity requirements. Rather than being able to borrow 95 cents against every dollar in assets $(\xi=0.95)$, we only allow banks to raise 90 cents in deposits $(\xi=0.90)$. This change lowers equilibrium bank leverage from $76.5 \%$ to $73.0 \%$. The regulatory capital constraint binds more frequently: $2.2 \%$ of the periods compared to $1.6 \%$ in the benchmark, and even more so in financial crises (19.6\% vs. 13.2\%). Bank deposits shrink by more than $3 \%$. Because the intermediary is better capitalized, she is better able to absorb the shocks. Her consumption growth volatility shrinks and her consumption share increases. Maybe surprisingly, it is the agent whose constraint is tightened that benefits from the policy change $(+1.28 \%)$.

Tighter bank capital requirements have a modest adverse effect on non-financial corporations. They face a slightly higher corporate bond rate. The equilibrium amount of corporate debt and the economy's capital stock shrink modestly. Firms' consumption growth volatility is slightly higher and their consumption share is unchanged, explaining the small welfare loss they suffer $(-0.19 \%)$. Effects on production are modest (-0.17\% decline in output).

Savers are also slightly worse off $(-0.08 \%)$ because their consumption, despite increasing as a share of output, also becomes slightly more volatile. They have to accommodate a more volatile supply of safe debt. The mean safe interest rate is 4 basis points higher, benefiting the saver but not enough to undo the volatility effect.

Overall, the welfare effect of tighter bank capital requirements is a welfare loss of $-0.10 \%$.

Combining Both The combined welfare effects from both macro-prudential policy changes are nearly additive for each agent. The aggregate welfare loss is $0.70 \%$. The main cost from the policy is a smaller economy. The main benefit is lower defaults, greater financial stability, and lower macroeconomic volatility. Financial leverage is mostly unchanged from the benchmark policy while corporate leverage is much reduced.

\section{Conclusion}

We provide the first calibrated macro-economic model which features banks who extend longterm defaultable loans to non-financial firms producing output and raise deposits from risk 
averse savers, and in which both banks and firms can default. The model incorporates a rich set a fiscal policy rules, including deposit insurance, and endogenizes the risk-free interest rate.

The model features a double financial accelerator. Like in the standard accelerator model, shocks to the macro-economy affect entrepreneurial net worth. Since firm borrowing is constrained by net worth, macro-economic shocks are amplified by tighter borrowing constraints. Unlike the original models, ours features impatient but risk averse and infinitely-lived entrepreneurs. The second financial accelerator arises from explicitly modeling the financial intermediaries' balance sheet as separate from that of the entrepreneur-borrowers and saving households. Intermediaries are subject to regulatory capital constraints. Macro-economic shocks that lead to binding intermediary borrowing constraints amplify the shocks through their direct effect on intermediaries' net worth and the indirect effect on borrowers to whom the intermediaries lend. However, in periods when intermediaries can absorb the fundamental shock without constraining the firms, they can short-circuit the first accelerator mechanism.

We provide a global nonlinear solution to this problem and a rich calibration to the U.S. economy. We explore the dynamics of quantities and prices in this setting and compare them to U.S. data, with a focus on understanding differences between financial and non-financial recessions. Our main application studies macro-prudential policy and contrasts restrictions on firm leverage to those on bank leverage. While such policies reduce the credit risk in the system and promote macro-economic stability and better risk sharing among the agents, they shrink the size of the economy and are ultimately welfare-reducing.

Our next steps are to introduce standard New Keyenesian elements such as nominal rigidities, monopolistic competition, and monetary policy. We believe our setting is an interesting one to evaluate the effect of the zero lower bound (ZLB) on nominal short rates. A binding ZLB during a financial crisis would keep the real rate elevated. Compared to a flexible price economy or one without a ZLB, where the real rate would fall, the ZLB economy would preclude a recapitalization of the intermediary through a negative real deposit rate. This force greatly mitigates the severity of financial recessions in the current model. Thus, a binding ZLB may lead to a severe crisis exactly because it prevents a recapitalization of financial intermediaries. 


\section{References}

Adrian, T., And N. Boyarchenko (2012): "Intermediary leverage cycles and financial stability," Working paper.

Bernanke, B. S., And M. Gertler (1989): "Agency Costs, Net Worth and Business Cycle Flutuations," American Economic Review, 79, 14-31.

Bernanke, B. S., M. Gertler, and S. Gilchrist (1996): "The Financial Accelerator and the Flight to Quality," The Review of Economics and Statistics, 78(1), 1-15.

(1999): "The financial accelerator in a quantitative business cycle framework," in Handbook of Macroeconomics, ed. by J. B. Taylor, and M. Woodford, vol. 1 of Handbook of Macroeconomics, chap. 21, pp. 1341-1393. Elsevier.

Bianchi, J., And E. Mendoza (2013): "Optimal Time-consistent Macroprudential Policy," NBER Working paper 19704.

— (2015): "Phases of Global Liquidity, Fundamentals News, and the Design of Macroprudential Policy," Working paper BIS No 505.

Brunnermeier, M. K., And Y. SAnnikov (2014): "A macroeconomic model with a financial sector," The American Economic Review, 104(2), 379-421.

Dang, T. V., G. Gorton, and B. Holmstrom (2015): "The Information Sensitivity of a Security," .

FARHi, E., And J. Tirole (2012): "Collective moral hazard, maturity mismatch, and systemic bailouts," Americcan Economic Review, pp. 60-93.

Farhi, E., And I. Werning (2014): "A Theory of Macroprudential Policies in the Presence of Nominal Rigidities," .

Friedman, B. M., And K. N. Kuttner (1993): Business Cycles, Indicators, and Forecastingchap. Why Does the Paper-Bill Spread Predict Real Economics Activity?, pp. 213-254. University of Chicago Press. 
Gârleanu, N., and L. H. Pedersen (2011): "Margin-based Asset Pricing and Deviations from the Law of One Price," Review of Financial Studies.

Gertler, M., And P. Karadi (2011): "A model of unconventional monetary policy," Journal of Monetary Economics, 58(1), 17-34.

Gilchrist, S., And E. Zakrajsek (2012): "Credit Spreads and Business Cycle Fluctuations," American Economic Review, 102, 1692-1720, Working Paper Boston University.

Greenwood, R., and S. G. Hanson (2013): "Issuer Quality and Corporate Bond Returns," The Review of Financial Studies, 26(6), 1483-1525.

Guerrieri, L., And M. Iacoviello (2015): "Occbin: A Toolkit to Solve Models with Occasionally Binding Constraints Easily," Journal of Monetary Economics, 70, 22-38.

Guerrieri, V., and G. Lorenzoni (2015): "Credit Crises, Precautionary Savings, and the Liquidity Trap," Working Paper University of Chicago and Northwestern University.

Hansen, G. D. (1985): "Indivisible Labor and the Business Cycle," Journal of Monetary Economics, 16, 309-327.

He, Z., and A. Krishnamurthy (2012): "A Model of Capital and Crises," The Review of Economic Studies, 79(2), 735-777.

He, Z., and A. Krishnamurthy (2013): "Intermediary asset pricing," American Economic Review, 103 (2), 732-770.

Jorda, O., M. Schularick, and A. Taylor (2014a): "Betting the House," NBER Working Paper No. 20771.

— (2014b): "The great mortgaging: housing finance, crises, and business cycles," Working Paper Series 2014-23, Federal Reserve Bank of San Francisco.

Kiyotaki, N., And J. Moore (1997): "Credit Cycles," Journal of Political Economy, 105(2), $211-48$.

Korinek, A. (2012): "Systemic Risk-Taking: Amplification Effects, Externalities, and Regulatory Responses," Working paper University of Maryland. 
Krishnamurthy, A., And T. Muir (2016): "Credit Spreads and the Severity of Financial Crises," .

Krishnamurthy, A., And A. Vissing-Jorgensen (2015): "The Impact of Financial Supply on Financial Sector Lending and Stability," Journal of Financial Economics, 118(2), 571-600.

Lopez-Salido, D., J. Stein, and E. Zakrajsek (2015): "Credit-Market Sentiment and the Business Cycle," Finance and Economics Discussion Series 2015-28, Board of Governors of the Federal Reserve System (U.S.).

Lorenzoni, G. (2008): "Inefficient Credit Booms," Review of Economic Studies, 75, 809-833.

MAGGionI, M. (2013): "Financial intermediation, international risk sharing, and reserve currencies," Working paper.

Mendoza, E. (2010): "Sudden Stops, Financial Crises, and Leverage," American Economic Review, 100, 1941-1966.

Mian, A., A. Sufi, and E. Verner (2016): "Household Debt and Business Cycle Worldwide," .

Moreira, A., And A. SaVov (2016): "The macroeconomics of shadow banking," The Journal of Finance.

Philippon, T. (2015): "Has the US Finance Industry Become Less Efficient?," American Economic Review, 105, 1408-1438.

Reinhart, C. M., and K. Rogoff (2009): This time is different: Eight centuries of financial folly. Princeton University Press.

Rouwenhorst, G. (1995): "Asset Pricing Implications of Equilibrium Business Cycle Models," in Frontiers of Business Cycle Research, ed. by Cooley. Princeton University Press. 


\section{A Model Appendix}

We reformulate the problem to ensure stationarity of the problem. We do so by scaling all variables by productivity.

\section{A.1 Borrower-entrepreneur problem}

\section{A.1.1 Preliminaries}

We start by defining some preliminaries.

$$
\begin{aligned}
& Z_{A}\left(\omega_{t}^{*}\right)=\left[1-F_{\omega}\left(\omega_{t}^{*} ; \chi\right)\right] \\
& Z_{K}\left(\omega_{t}^{*}\right)=\left[1-F_{\omega}\left(\omega_{t}^{*} ; \chi\right)\right] \mathrm{E}\left[w_{i, t} \mid \omega_{i, t} \geq \omega_{t}^{*} ; \chi\right]
\end{aligned}
$$

and $F_{\omega}(\cdot ; \chi)$ is the CDF of $\omega_{i, t}$ with parameters $\chi$. Assume $\omega_{i, t}$ are drawn from a Gamma distribution with shape and scale parameters $\chi=\left(\chi_{0}, \chi_{1}\right)$ such that

$$
\begin{aligned}
\mu_{\omega}=\mathrm{E}_{i}\left[\omega_{i, t} ; \chi_{0}, \chi_{1}\right] & =\chi_{0} \chi_{1} \\
\sigma_{t, \omega}^{2}=\operatorname{Var}_{i}\left[\omega_{i, t} ; \chi_{0}, \chi_{1}\right] & =\chi_{0} \chi_{1}^{2}
\end{aligned}
$$

From Landsman and Valdez (2004, equation 22), we know that

$$
\mathrm{E}[\omega \mid \omega \geq \bar{\omega}]=\mu_{\omega} \frac{1-F_{\omega}\left(\bar{\omega} ; \chi_{0}+1, \chi_{1}\right)}{1-F_{\omega}\left(\bar{\omega} ; \chi_{0}, \chi_{1}\right)}
$$

so the closed form expression for $Z_{K}$ is

$$
Z_{K}\left(\omega_{t}^{*}\right)=\mu_{\omega}\left[1-F_{\omega}\left(\omega_{t}^{*} ; \chi_{0}+1, \chi_{1}\right)\right]
$$

It is useful to compute the derivatives of $Z_{K}(\cdot)$ and $Z_{A}(\cdot)$ :

$$
\begin{aligned}
& \frac{\partial Z_{K}\left(\omega_{t}^{*}\right)}{\partial \omega_{t}^{*}}=\frac{\partial}{\partial \omega_{t}^{*}} \int_{\omega_{t}^{*}}^{\infty} \omega f_{\omega}(\omega) d \omega=-\omega_{t}^{*} f_{\omega}\left(\omega_{t}^{*}\right), \\
& \frac{\partial Z_{A}\left(\omega_{t}^{*}\right)}{\partial \omega_{t}^{*}}=\frac{\partial}{\partial \omega_{t}^{*}} \int_{\omega_{t}^{*}}^{\infty} f_{\omega}(\omega) d \omega=-f_{\omega}\left(\omega_{t}^{*}\right),
\end{aligned}
$$

where $f_{\omega}(\cdot)$ is the p.d.f. of a Gamma distribution with parameters $\left(\chi_{0}, \chi_{1}\right)$.

Capital Adjustment Cost Let

$$
\Psi\left(X_{t}, K_{t}^{B}\right)=\frac{\psi}{2}\left(\frac{X_{t}}{K_{t}^{B}}-\left(e^{\bar{g}}-\mu_{\omega}\right)\right)^{2} K_{t}^{B} .
$$


Then partial derivatives are

$$
\begin{aligned}
& \Psi_{X}\left(X_{t}, K_{t}^{B}\right)=\psi\left(\frac{X_{t}}{K_{t}^{B}}-\left(e^{\bar{g}}-\mu_{\omega}\right)\right) \\
& \Psi_{K}\left(X_{t}, K_{t}^{B}\right)=-\frac{\psi}{2}\left(\left(\frac{X_{t}}{K_{t}^{B}}\right)^{2}-\left(e^{\bar{g}}-\mu_{\omega}\right)^{2}\right)
\end{aligned}
$$

\section{A.1.2 Statement of stationary problem}

We consider the borrower's problem in the current period after productivity and depreciation shocks have been realized, after the intermediary has chosen a default policy, and after the intermediary's random utility penalty is realized. To ensure stationarity of the borrowerentrepreneur's problem we define the following transformed variables,

$$
\left\{\hat{C}_{t}^{B}, \hat{X}_{t}, \hat{A}_{t}^{B}, \hat{K}_{t}^{B}, \hat{w}_{t}^{j}, \hat{G}_{t}^{T, B}\right\}
$$

where for any variable $v \hat{a} r_{t}$ denotes division by the current realization of productivity $Z_{t}$ :

$$
\text { vâr } r_{t}=\frac{v a r_{t}}{Z_{t}} .
$$

It follows that transformed output is $\hat{Y}_{t}=\left(\hat{K}_{t}^{B}\right)^{1-\alpha} L_{t}^{\alpha}$. For the choices of capital and debt for the next period we further define

$$
\hat{\hat{K}}_{t+1}^{B}=\frac{K_{t+1}^{B}}{Z_{t}}
$$

and

$$
\hat{\hat{A}}_{t+1}^{B}=\frac{A_{t+1}^{B}}{Z_{t}} .
$$

Let $\mathcal{S}_{t}^{B}=\left(g_{t}, \sigma_{\omega, t}, \hat{W}_{t}^{I}, \hat{W}_{t}^{S}, \hat{B}_{t-1}^{G}\right)$ represent state variables exogenous to the borrowerentrepreneur's decision. Then the borrower's value function, transformed to ensure stationarity, is:

$$
\begin{aligned}
\hat{V}^{B}\left(\hat{K}_{t}^{B}, \hat{A}_{t}^{B}, \mathcal{S}_{t}^{B}\right)= & \max _{\left\{\hat{C}_{t}^{B}, \hat{\hat{K}}_{t+1}^{B}, \omega_{t}^{*}, \hat{X}_{t}, \hat{\hat{A}}_{t+1}^{B}, L_{t}^{j}\right\}}\left\{\left(1-\beta_{B}\right)\left(\hat{C}_{t}^{B}\right)^{1-1 / \nu}+\right. \\
& \left.+\beta_{B} \mathrm{E}_{t}\left[\left(e^{g_{t+1}} \tilde{\hat{V}}^{B}\left(e^{-g_{t+1}} \hat{\hat{K}}_{t+1}^{B}, e^{-g_{t+1}} \hat{\hat{A}}_{t+1}^{B}, \mathcal{S}_{t+1}^{B}\right)\right)^{1-\sigma_{B}}\right]^{\frac{1-1 / \nu}{1-\sigma_{B}}}\right\}^{\frac{1}{1-1 / \nu}}
\end{aligned}
$$


subject to

$$
\begin{aligned}
\hat{C}_{t}^{B}= & \left(1-\tau_{\Pi}^{I}\right) \hat{Y}_{t}^{B}+\left(1-\tau_{t}^{B}\right) \hat{w}_{t}^{B} \bar{L}^{B}+\hat{G}_{t}^{T, B}+p_{t}\left[\hat{X}_{t}+\left(Z_{K}\left(\omega_{t}^{*}\right)+\tau_{\Pi}^{I} \delta_{K} Z_{A}\left(\omega_{t}^{*}\right)\right) \hat{K}_{t}^{B}\right] \\
& +q_{t}^{m} \hat{\hat{A}}_{t+1}^{B}-Z_{A}\left(\omega_{t}^{*}\right) \hat{A}_{t}^{B}\left(1-(1-\theta) \tau_{\Pi}^{I}+\delta q_{t}^{m}\right) \\
& \quad-p_{t} \hat{\hat{K}}_{t+1}^{B}-\hat{X}_{t}-\Psi\left(\hat{X}_{t}, \hat{K}_{t}^{B}\right)-\left(1-\tau_{\Pi}^{I}\right) \sum_{j=B, I, S} \hat{w}_{t}^{j} L_{t}^{j} \\
\phi p_{t} Z_{K}\left(\omega_{t}^{*}\right) \hat{K}_{t}^{B} \geq & F \hat{\hat{A}}_{t+1}^{B} \\
\mathcal{S}_{t+1}^{B}= & h\left(\mathcal{S}_{t}^{B}\right)
\end{aligned}
$$

where the functions $Z_{K}$ and $Z_{A}$ are defined in the preliminaries above.

The continuation value $\tilde{V}^{B}(\cdot)$ must take into account the default decision of the risk taker at the beginning of next period. We anticipate here and show below that that default decision takes the form of a cutoff rule:

$$
\begin{aligned}
\tilde{\hat{V}}^{B}\left(\hat{K}_{t}^{B}, \hat{A}_{t}^{B}, \mathcal{S}_{t}^{B}\right) & =F_{\rho}\left(\rho_{t}^{*}\right) \mathrm{E}_{\rho}\left[\hat{V}^{B}\left(\hat{K}_{t}^{B}, \hat{A}_{t}^{B}, \mathcal{S}_{t}^{B}\right) \mid \rho<\rho_{t}^{*}\right]+\left(1-F_{\rho}\left(\rho_{t}^{*}\right)\right) \mathrm{E}_{\rho}\left[\hat{V}^{B}\left(\hat{K}_{t}^{B}, \hat{A}_{t}^{B}, \mathcal{S}_{t}^{B}\right) \mid \rho>\rho_{t}^{*}\right] \\
& =F_{\rho}\left(\rho_{t}^{*}\right) \hat{V}^{B}\left(\hat{K}_{t}^{B}, \hat{A}_{t}^{B}, \mathcal{S}_{t}^{S}\left(\rho_{t}<\rho_{t}^{*}\right)\right)+\left(1-F_{\rho}\left(\rho_{t}^{*}\right)\right) \hat{V}^{B}\left(\hat{K}_{t}^{B}, \hat{A}_{t}^{B}, \mathcal{S}_{t}^{S}\left(\rho_{t}>\rho_{t}^{*}\right)\right)
\end{aligned}
$$

where (21) obtains because the expectation terms conditional on realizations of $\rho_{t}$ and $\rho_{t}^{*}$ only differ in the values of the aggregate state variables.

Denote the value function and the partial derivatives of the value function as:

$$
\begin{aligned}
\hat{V}_{t}^{B} & \equiv \hat{V}\left(\hat{K}_{t}^{B}, \hat{A}_{t}^{B}, \mathcal{S}_{t}^{B}\right), \\
\hat{V}_{A, t}^{B} & \equiv \frac{\partial \hat{V}\left(\hat{K}_{t}^{B}, \hat{A}_{t}^{B}, \mathcal{S}_{t}^{B}\right)}{\partial \hat{A}_{t}^{B}}, \\
\hat{V}_{K, t}^{B} & \equiv \frac{\partial \hat{V}\left(\hat{K}_{t}^{B}, \hat{A}_{t}^{B}, \mathcal{S}_{t}^{B}\right)}{\partial \hat{K}_{t}^{B}} .
\end{aligned}
$$

Therefore the marginal values of borrowing and of capital of $\tilde{V}^{B}(\cdot)$ are:

$$
\begin{aligned}
& \tilde{\hat{V}}_{A, t}^{B}=F_{\rho}\left(\rho_{t}^{*}\right) \frac{\partial \hat{V}^{B}\left(\hat{K}_{t}^{B}, \hat{A}_{t}^{B}, \mathcal{S}_{t}^{B}\left(\rho_{t}<\rho_{t}^{*}\right)\right)}{\partial \hat{A}_{t}^{B}}+\left(1-F_{\rho}\left(\rho_{t}^{*}\right)\right) \frac{\partial \hat{V}^{B}\left(\hat{K}_{t}^{B}, \hat{A}_{t}^{B}, \mathcal{S}_{t}^{B}\left(\rho_{t}>\rho_{t}^{*}\right)\right)}{\partial \hat{A}_{t}^{B}} \\
& \tilde{\hat{V}}_{K, t}^{B}=F_{\rho}\left(\rho_{t}^{*}\right) \frac{\partial \hat{V}^{B}\left(\hat{K}_{t}^{B}, \hat{A}_{t}^{B}, \mathcal{S}_{t}^{B}\left(\rho_{t}<\rho_{t}^{*}\right)\right)}{\partial \hat{K}_{t}^{B}}+\left(1-F_{\rho}\left(\rho_{t}^{*}\right)\right) \frac{\partial \hat{V}^{B}\left(\hat{K}_{t}^{B}, \hat{A}_{t}^{B}, \mathcal{S}_{t}^{B}\left(\rho_{t}>\rho_{t}^{*}\right)\right)}{\partial \hat{K}_{t}^{B}}
\end{aligned}
$$

Denote the certainty equivalent of future utility as:

$$
C E_{t}^{B}=\mathrm{E}_{t}\left[\left(e^{g_{t+1}} \tilde{\hat{V}}^{B}\left(\hat{K}_{t+1}^{B}, \hat{A}_{t+1}^{B}, \mathcal{S}_{t+1}^{B}\right)\right)^{1-\sigma_{B}}\right]^{\frac{1}{1-\sigma_{B}}}
$$




\section{A.1.3 First-order conditions}

Loans The FOC for loans $\hat{\hat{A}}_{t+1}^{B}$ is:

$$
\begin{aligned}
& 0=\frac{1}{1-1 / \nu}\left\{\left(1-\beta_{B}\right)\left[\hat{C}_{t}^{B}\right]^{1-1 / \nu}+\right. \\
& \left.\quad+\beta_{B} \mathrm{E}_{t}\left[\left(e^{g_{t+1}} \hat{\hat{V}}^{B}\left(\hat{K}_{t+1}^{B}, \hat{A}_{t+1}^{B}, \mathcal{S}_{t+1}^{B}\right)\right)^{1-\sigma_{B}}\right]^{\frac{1-1 / \nu}{1-\sigma_{B}}}\right\}^{\frac{1}{1-1 / \nu}-1} \times \\
& \quad \times\left\{(1-1 / \nu)\left(1-\beta_{B}\right)\left[\hat{C}_{t}^{B}\right]^{-1 / \nu} q_{t}^{m}+\right. \\
& \quad+\beta_{B} \frac{1-1 / \nu}{1-\sigma_{B}} \mathrm{E}_{t}\left[\left(e^{g_{t+1}} \tilde{\hat{V}}^{B}\left(\hat{K}_{t+1}^{B}, \hat{A}_{t+1}^{B}, \mathcal{S}_{t+1}^{B}\right)\right)^{1-\sigma_{B}}\right]^{\frac{1-1 / \nu}{1-\sigma_{B}}-1} \times \\
& \left.\quad \times E_{t}\left[\left(1-\sigma_{B}\right)\left(e^{g_{t+1}} \tilde{\hat{V}}^{B}\left(\hat{K}_{t+1}^{B}, \hat{A}_{t+1}^{B}, \mathcal{S}_{t+1}^{B}\right)\right)^{-\sigma_{B}} e^{g_{t+1}} \tilde{\hat{V}}_{A, t+1}^{B} e^{-g_{t+1}}\right]\right\}-\lambda_{t}^{B} F
\end{aligned}
$$

where $\lambda_{t}^{B}$ is the Lagrange multiplier on the borrowing constraint.

Simplifying, we get:

$$
\begin{aligned}
& q_{t}^{m}\left(\hat{C}_{t}^{B}\right)^{-1 / \nu}\left(1-\beta_{B}\right)\left(\hat{V}_{t}^{B}\right)^{1 / \nu}= \\
& \quad \lambda_{t}^{B} F-\beta_{B} \mathrm{E}_{t}\left[\left(e^{g_{t+1}} \tilde{\hat{V}}_{t+1}^{B}\right)^{-\sigma_{B}} \tilde{\hat{V}}_{A, t+1}^{B}\right]\left(C E_{t}^{B}\right)^{\sigma_{B}-1 / \nu}\left(V_{t}^{B}\right)^{1 / \nu}
\end{aligned}
$$

Observe that we can rewrite equation (22) as:

$$
q_{t}^{m}=\frac{\left(\hat{C}_{t}^{B}\right)^{1 / \nu}}{\left(1-\beta_{B}\right)\left(\hat{V}_{t}^{B}\right)^{1 / \nu}}\left\{\lambda_{t}^{B} F-\beta_{B} \mathrm{E}_{t}\left[\left(e^{g_{t+1}} \tilde{\hat{V}}_{t+1}^{B}\right)^{-\sigma_{B}} \tilde{\hat{V}}_{A, t+1}^{B}\right]\left(C E_{t}^{B}\right)^{\sigma_{B}-1 / \nu}\left(\hat{V}_{t}^{B}\right)^{1 / \nu}\right\}
$$

We define the rescaled Lagrange multiplier of the borrower as the original multiplier divided by marginal utility of current consumption:

$$
\tilde{\lambda}_{t}^{B}=\lambda_{t}^{B} \frac{\left(\hat{C}_{t}^{B}\right)^{1 / \nu}}{\left(1-\beta_{B}\right)\left(\hat{V}_{t}^{B}\right)^{1 / \nu}} .
$$

Then we can solve for the mortgage price as:

$$
q_{t}^{m}=\tilde{\lambda}_{t}^{B} F-\beta_{B} \frac{\left(\hat{C}_{t}^{B}\right)^{1 / \nu}}{\left(1-\beta_{B}\right)\left(\hat{V}_{t}^{B}\right)^{1 / \nu}} \mathrm{E}_{t}\left[\left(e^{g t+1} \tilde{\hat{V}}_{t+1}^{B}\right)^{-\sigma_{B}} \tilde{\hat{V}}_{A, t+1}^{B}\right]\left(C E_{t}^{B}\right)^{\sigma_{B}-1 / \nu}\left(\hat{V}_{t}^{B}\right)^{1 / \nu} .
$$


Capital The FOC for new purchases of capital $\hat{\hat{K}}_{t+1}^{B}$ is:

$$
\begin{aligned}
& 0=\frac{1}{1-1 / \nu}\left(\hat{V}_{t}^{B}\right)^{1 / \nu} \times\left\{-(1-1 / \nu)\left(1-\beta_{B}\right)\left(\hat{C}_{t}^{B}\right)^{-1 / \nu} p_{t}+\right. \\
& \left.\quad+\frac{1-1 / \nu}{1-\sigma_{B}} \beta_{B}\left(C E_{t}^{B}\right)^{\sigma_{B}-1 / \nu} \mathrm{E}_{t}\left[\left(1-\sigma_{B}\right)\left(e^{g_{t+1}} \tilde{\hat{V}}_{t+1}^{B}\right)^{-\sigma_{B}} e^{g_{t+1}} \tilde{\hat{V}}_{K, t+1}^{B} e^{-g_{t+1}}\right]\right\} .
\end{aligned}
$$

Simplifying, we get:

$$
\begin{aligned}
& p_{t} \frac{\left(1-\beta_{B}\right)\left(\hat{V}_{t}^{B}\right)^{1 / \nu}}{\left(\hat{C}_{t}^{B}\right)^{1 / \nu}}= \\
& \beta_{B} \mathrm{E}_{t}\left[\left(e^{g_{t+1}} \tilde{\hat{V}}_{t+1}^{B}\right)^{-\sigma_{B}} \tilde{\hat{V}}_{K, t+1}^{B}\right]\left(C E_{t}^{B}\right)^{\sigma_{B}-1 / \nu}\left(\hat{V}_{t}^{B}\right)^{1 / \nu}
\end{aligned}
$$

Default Threshold Taking the first-order condition with respect to $\omega_{t}^{\star}$ and using the expressions for the derivatives of $Z_{K}(\cdot)$ and $Z_{A}(\cdot)$ in the preliminaries above yields:

$$
f_{\omega}\left(\omega_{t}^{*}\right)\left[\omega_{t}^{*} p_{t} \hat{K}_{t}^{B}\left(1+\phi \tilde{\lambda}_{t}^{B}\right)-\left(1-(1-\theta) \tau_{\Pi}^{I}+\delta q_{t}^{m}\right) \hat{A}_{t}^{B}\right] \frac{\left(1-\beta_{B}\right)\left(\hat{V}_{t}^{B}\right)^{1 / \nu}}{\left(\hat{C}_{t}^{B}\right)^{1 / \nu}}=0
$$

This can be simplified to give:

$$
\omega_{t}^{*}=\frac{\hat{A}_{t}^{B}\left(1-(1-\theta) \tau_{\Pi}^{I}+\delta q_{t}^{m}\right)}{p_{t} \hat{K}_{t}^{B}\left(1+\phi \tilde{\lambda}_{t}^{B}\right)} .
$$

Investment The FOC for investment $\hat{X}_{t}$ is:

$$
\left[1+\Psi_{X}\left(\hat{X}_{t}^{B}, \hat{K}_{t}^{B}\right)-p_{t}\right] \frac{\left(1-\beta_{B}\right)\left(\hat{V}_{t}^{B}\right)^{1 / \nu}}{\left(\hat{C}_{t}^{B}\right)^{1 / \nu}}=0
$$

which simplifies to

$$
1+\Psi_{X}\left(\hat{X}_{t}^{B}, \hat{K}_{t}^{B}\right)=p_{t}
$$

Labor Inputs Defining $\gamma_{B}=1-\gamma_{I}-\gamma_{S}$, aggregate labor input is

$$
L_{t}=\prod_{j=B, I, S}\left(L_{t}^{j}\right)^{\gamma_{j}} .
$$

The FOC for labor input $L_{t}^{j}$ is then

$$
\left(1-\tau^{\Pi}\right)\left[\alpha \gamma_{j} \frac{L_{t}}{L_{t}^{j}}\left(\frac{\hat{K}_{t}^{B}}{L_{t}}\right)^{1-\alpha}-\hat{w}_{t}^{j}\right] \frac{\left(1-\beta_{B}\right)\left(\hat{V}_{t}^{B}\right)^{1 / \nu}}{\left(\hat{C}_{t}^{B}\right)^{1 / \nu}}=0
$$


which yields

$$
\alpha \gamma_{j} \frac{L_{t}}{L_{t}^{j}}\left(\frac{\hat{K}_{t}^{B}}{L_{t}}\right)^{1-\alpha}=\hat{w}_{t}^{j}
$$

\section{A.1.4 Marginal Values of State Variables and SDF}

Loans Taking the derivative of the value function with respect to $\hat{A}_{t}^{B}$ gives:

$$
\hat{V}_{A, t}^{B}=-\left(1-(1-\theta) \tau_{\Pi}^{I}+\delta q_{t}^{m}\right) Z_{A}\left(\omega_{t}^{*}\right) \frac{\left(1-\beta_{B}\right)\left(\hat{V}_{t}^{B}\right)^{1 / \nu}}{\left(\hat{C}_{t}^{B}\right)^{1 / \nu}} .
$$

Capital Taking the derivative of the value function with respect to $\hat{K}_{t}^{B}$ gives:

$$
\begin{aligned}
\hat{V}_{K, t}^{B}= & {\left[p_{t}\left(Z_{K}\left(\omega_{t}^{*}\right)\left(1+\phi \tilde{\lambda}_{t}^{B}\right)+\tau_{\Pi}^{I} \delta_{K} Z_{A}\left(\omega_{t}^{*}\right)\right)+(1-\alpha)\left(1-\tau_{I}^{\Pi}\right)\left(\frac{\hat{K}_{t}^{B}}{L_{t}}\right)^{-\alpha}-\Psi_{K}\left(\hat{X}_{t}^{B}, \hat{K}_{t}^{B}\right)\right] } \\
& \times \frac{\left(1-\beta_{B}\right)\left(\hat{V}_{t}^{B}\right)^{1 / \nu}}{\left(\hat{C}_{t}^{B}\right)^{1 / \nu}} .
\end{aligned}
$$

SDF Define the borrower-entrepreneur's intertemporal marginal rate of substitution between $t$ and $t+1$, conditional on a particular realization of $\rho_{t+1}$ as:

$$
\begin{aligned}
\mathcal{M}_{t, t+1}^{B}\left(\rho_{t+1}\right) & =\frac{\partial V_{t}^{B} / \partial \hat{C}_{t+1}^{B}}{\partial \hat{V}_{t}^{B} / \partial \hat{C}_{t}^{B}}=\frac{\partial \hat{V}_{t}^{B}}{\partial \hat{V}_{t+1}^{B}\left(\rho_{t+1}\right)} e^{-g_{t+1}} \frac{\partial \hat{V}_{t+1}^{B} / \partial \hat{C}_{t+1}^{B}}{\partial \hat{V}_{t}^{B} / \partial \hat{C}_{t}^{B}} \\
& =\left(\hat{V}_{t}^{B}\right)^{1 / \nu} \beta_{B}\left(C E_{t}^{B}\right)^{\sigma_{B}-1 / \nu}\left(e^{g_{t+1}} \tilde{\hat{V}}_{t+1}^{B}\left(\rho_{t+1}\right)\right)^{-\sigma_{B}} \frac{\left(\hat{C}_{t+1}^{B}\right)^{-1 / \nu}\left(1-\beta_{B}\right)\left(\hat{V}_{t+1}^{B}\left(\rho_{t+1}\right)\right)^{1 / \nu}}{\left(\hat{C}_{t}^{B}\right)^{-1 / \nu}\left(1-\beta_{B}\right)\left(\hat{V}_{t}^{B}\right)^{1 / \nu}} \\
& =\beta_{B} e^{-\sigma_{B} g_{t+1}}\left(\frac{\hat{C}_{t+1}^{B}}{\hat{C}_{t}^{B}}\right)^{-1 / \nu}\left(\frac{\hat{V}_{t+1}^{B}\left(\rho_{t+1}\right)}{C E_{t}^{B}}\right)^{-\left(\sigma_{B}-1 / \nu\right)}
\end{aligned}
$$

We can then define the stochastic discount factor (SDF) of borrowers as:

$$
\tilde{\mathcal{M}}_{t, t+1}^{B}=F_{\rho}\left(\rho_{t+1}^{*}\right) \mathcal{M}_{t, t+1}^{B}\left(\rho_{t+1}<\rho_{t+1}^{*}\right)+\left(1-F_{\rho}\left(\rho_{t+1}^{*}\right)\right) \mathcal{M}_{t, t+1}^{B}\left(\rho_{t+1}>\rho_{t+1}^{*}\right)
$$

where $\mathcal{M}_{t, t+1}^{B}\left(\rho_{t+1}<\rho_{t+1}^{*}\right)$ and $\mathcal{M}_{t, t+1}^{B}\left(\rho_{t+1}>\rho_{t+1}^{*}\right)$ are the IMRSs, conditional on the two possible realizations of state variables.

\section{A.1.5 Euler Equations}

Loans Recall that $\tilde{\hat{V}}_{A, t+1}^{B}$ is a linear combination of $\hat{V}_{A, t+1}^{B}$ conditional on $\rho_{t}$ being below and above the threshold, and with each $\hat{V}_{A, t+1}^{B}$ given by equation (28). Substituting in for $\tilde{\hat{V}}_{A, t+1}^{B}$ in 
(22) and using the SDF expression, we get the recursion:

$$
q_{t}^{m}=\tilde{\lambda}_{t}^{B} F+\mathrm{E}_{t}\left[\tilde{\mathcal{M}}_{t, t+1}^{B} Z_{A}\left(\omega_{t+1}^{*}\right)\left(1-(1-\theta) \tau_{\Pi}^{I}+\delta q_{t+1}^{m}\right)\right] .
$$

Capital Likewise, observe that we can write (24) as:

$$
p_{t}=\frac{\beta_{B} \mathrm{E}_{t}\left[e^{g_{t+1}}\left(\tilde{\hat{V}}_{t+1}^{B}\right)^{-\sigma_{B}} \tilde{\hat{V}}_{K, t+1}^{B}\right]\left(C E_{t}^{B}\right)^{\sigma_{B}-1 / \nu}\left(\hat{V}_{t}^{B}\right)^{1 / \nu}}{\left(\hat{C}_{t}^{B}\right)^{-1 / \nu}\left(1-\beta_{B}\right)\left(\hat{V}_{t}^{B}\right)^{1 / \nu}}
$$

Recall that $\tilde{\hat{V}}_{K, t+1}^{B}$ is a linear combination of $\hat{V}_{K, t+1}^{B}$ conditional on $\rho_{t}$ being below and above the threshold, and with each $\hat{V}_{K, t+1}^{B}$ given by equation (29). Substituting in for $\tilde{\hat{V}}_{K, t+1}^{B}$ and using the SDF expression, we get the recursion:

$$
\begin{aligned}
p_{t}=\mathrm{E}_{t} & {\left[\tilde { \mathcal { M } } _ { t , t + 1 } ^ { B } \left\{p_{t+1}\left(Z_{K}\left(\omega_{t+1}^{*}\right)\left(1+\phi \tilde{\lambda}_{t+1}^{B}\right)+\tau_{\Pi}^{I} \delta_{K} Z_{A}\left(\omega_{t+1}^{*}\right)\right)\right.\right.} \\
& \left.\left.+(1-\alpha)\left(1-\tau^{\Pi}\right)\left(\frac{\hat{K}_{t+1}^{B}}{L_{t+1}}\right)^{-\alpha}-\Psi_{K}\left(\hat{X}_{t+1}, \hat{K}_{t+1}^{B}\right)\right\}\right] .
\end{aligned}
$$

\section{A.2 Intermediaries}

\section{A.2.1 Statement of stationary problem}

As for borrower-entrepreneurs, we define the following transformed variables for intermediaries:

$$
\left\{\hat{W}_{t}^{I}, \hat{C}_{t}^{I}, \hat{A}_{t+1}^{I}, \hat{G}_{t}^{T, I}, \hat{B}_{t}^{I}\right\}
$$

Denote by $\hat{W}_{t}^{I}$ risk taker wealth at the beginning of the period, before their bankruptcy decision. Then wealth after realization of the penalty $\rho_{t}$ is:

$$
\tilde{\hat{W}}_{t}^{I}=\left(1-D\left(\rho_{t}\right)\right) \hat{W}_{t}^{I},
$$

and the effective utility penalty is:

$$
\tilde{\rho}_{t}=D\left(\rho_{t}\right) \rho_{t}
$$

Let $\mathcal{S}_{t}^{I}=\left(g_{t}, \sigma_{\omega, t}, \hat{K}_{t}^{B}, \hat{A}_{t}^{B}, \hat{B}_{t-1}^{G}, \hat{W}_{t}^{S}\right)$ denote all other aggregate state variables exogenous to intermediaries.

After the default decision, intermediaries face the following optimization problem over consumption and portfolio composition, formulated to ensure stationarity:

$\hat{V}^{I}\left(\tilde{\hat{W}} t_{t}^{I}, \tilde{\rho}_{t}, \mathcal{S}_{t}^{I}\right)=\max _{\hat{C}_{t}^{I}, \hat{A}_{t+1}^{I}, \hat{B}_{t}^{I}}\left\{\left(1-\beta_{I}\right)\left[\frac{\hat{C}_{t}^{I}}{e^{\tilde{\rho}_{t}}}\right]^{1-1 / \nu}+\beta_{I} \mathrm{E}_{t}\left[\left(e^{g_{t+1}} \tilde{\hat{V}}^{I}\left(\hat{W}_{t+1}^{I}, \mathcal{S}_{t+1}^{I}\right)\right)^{1-\sigma_{R}}\right]^{\frac{1-1 / \nu}{1-\sigma_{R}}}\right\}^{\frac{1}{1-1 / \nu}}$ 
subject to:

$$
\begin{aligned}
\left(1-\tau^{I}\right) \hat{w}_{t}^{I} \bar{L}^{I}+\tilde{\hat{W}}_{t}^{I}+\hat{G}_{t}^{T, I} & =\hat{C}_{t}^{I}+q_{t}^{m} \hat{A}_{t+1}^{I}+\left(q_{t}^{f}+\tau_{I}^{\Pi} r_{t}^{f}-\kappa I_{\left\{\hat{B}_{t}^{I}<0\right\}}\right) \hat{B}_{t}^{I}, \\
\hat{W}_{t+1}^{I} & =e^{-g_{t+1}}\left[\left(\tilde{M}_{t+1}+Z_{A}\left(\omega_{t+1}^{*}\right) \delta q_{t+1}^{m}\right) \hat{A}_{t+1}^{I}+\hat{B}_{t}^{I}\right], \\
q_{t}^{f} \hat{B}_{t}^{I} & \geq-\xi q_{t}^{m} \hat{A}_{t+1}^{I}, \\
\hat{A}_{t+1}^{R} & \geq 0, \\
\mathcal{S}_{t+1}^{I} & =h\left(\mathcal{S}_{t}^{I}\right) .
\end{aligned}
$$

For the statement of the problem above, we have defined the after-tax payoff per bond as

$$
\tilde{M}_{t}=Z_{A}\left(\omega_{t}^{*}\right)\left(1-(1-\theta) \tau_{\Pi}^{I}\right)+\frac{(1-\zeta)\left(\mu_{\omega}-Z_{K}\left(\omega_{t}^{*}\right)\right) p_{t} K_{t}^{B}}{A_{t}^{B}} .
$$

The continuation value $\tilde{\hat{V}}^{I}\left(\hat{W}_{t+1}^{I}, \mathcal{S}_{t+1}^{I}\right)$ is the outcome of the optimization problem intermediaries face at the beginning of the following period, i.e., before the decision over the optimal bankruptcy rule. This continuation value function is given by:

$$
\tilde{\hat{V}}^{I}\left(\hat{W}_{t}^{I}, \mathcal{S}_{t}^{I}\right)=\max _{D(\rho)} \mathrm{E}_{\rho}\left[D(\rho) \hat{V}^{I}\left(0, \rho, \mathcal{S}_{t}^{I}\right)+(1-D(\rho)) \hat{V}^{I}\left(\hat{W}_{t}^{I}, 0, \mathcal{S}_{t}^{I}\right)\right]
$$

Define the certainty equivalent of future utility as:

$$
C E_{t}^{I}=\mathrm{E}_{t}\left[\left(e^{g_{t+1}} \tilde{\hat{V}}^{I}\left(\hat{W}_{t+1}^{I}, \mathcal{S}_{t+1}^{I}\right)\right)^{1-\sigma_{I}}\right]^{\frac{1}{1-\sigma_{I}}}
$$

\section{A.2.2 First-order conditions}

Optimal Default Decision The optimization consists of choosing a function $D(\rho): \mathbb{R} \rightarrow$ $\{0,1\}$ that specifies for each possible realization of the penalty $\rho$ whether or not to default.

Since the value function $\hat{V}^{I}\left(W, \rho, \mathcal{S}_{t}^{R}\right)$ defined in (32) is increasing in wealth $W$ and decreasing in the penalty $\rho$, there will generally exist an optimal threshold penalty $\rho^{*}$ such that for a given $\hat{W}_{t}^{I}$, intermediaries optimally default for all realizations $\rho<\rho^{*}$. Hence we can equivalently write the optimization problem in (38) as

$$
\begin{aligned}
\tilde{\hat{V}}^{I}\left(\hat{W}_{t}^{I}, \mathcal{S}_{t}^{R}\right) & =\max _{\rho^{*}} \mathrm{E}_{\rho}\left[\mathbb{1}\left[\rho<\rho^{*}\right] \hat{V}^{I}\left(0, \rho, \mathcal{S}_{t}^{I}\right)+\left(1-\mathbb{1}\left[\rho<\rho^{*}\right]\right) \hat{V}^{I}\left(\hat{W}_{t}^{I}, 0, \mathcal{S}_{t}^{I}\right)\right] \\
& =\max _{\rho^{*}} F_{\rho}\left(\rho^{*}\right) \mathrm{E}_{\rho}\left[\hat{V}^{I}\left(0, \rho, \mathcal{S}_{t}^{I}\right) \mid \rho<\rho^{*}\right]+\left(1-F_{\rho}\left(\rho^{*}\right)\right) \hat{V}^{I}\left(\hat{W}_{t}^{I}, 0, \mathcal{S}_{t}^{I}\right) .
\end{aligned}
$$

The solution $\rho_{t}^{*}$ is characterized by the first-order condition:

$$
\hat{V}^{I}\left(0, \rho_{t}^{*}, \mathcal{S}_{t}^{I}\right)=\hat{V}^{I}\left(\hat{W}_{t}^{I}, 0, \mathcal{S}_{t}^{I}\right) .
$$


By defining the partial inverse $\mathcal{F}:(0, \infty) \rightarrow(-\infty, \infty)$ of $\hat{V}^{I}(\cdot)$ in its second argument as

$$
\left\{(x, y): y=\mathcal{F}(x) \Leftrightarrow x=\hat{V}^{I}(0, y)\right\}
$$

we get that

$$
\rho_{t}^{*}=\mathcal{F}\left(\hat{V}^{I}\left(\hat{W}_{t}^{I}, 0, \mathcal{S}_{t}^{I}\right)\right)
$$

and by substituting the solution into (38), we obtain

$$
\tilde{\hat{V}}^{I}\left(\hat{W}_{t}^{I}, \mathcal{S}_{t}^{I}\right)=F_{\rho}\left(\rho_{t}^{*}\right) \mathrm{E}_{\rho}\left[\hat{V}^{I}\left(0, \rho, \mathcal{S}_{t}^{I}\right) \mid \rho<\rho_{t}^{*}\right]+\left(1-F_{\rho}\left(\rho_{t}^{*}\right)\right) \hat{V}^{I}\left(\hat{W}_{t}^{I}, 0, \mathcal{S}_{t}^{I}\right) .
$$

Equations (32), (40), and (41) completely characterize the optimization problem of risk-takers.

To compute the optimal bankruptcy threshold $\rho_{t}^{*}$, note that the inverse value function defined in equation (40) is given by:

$$
\mathcal{F}(x)=\left\{\begin{array}{l}
\log \left(\left(1-\beta_{I}\right) \hat{C}_{t}^{I}\right)-\frac{1}{1-1 / \nu} \log \left(x^{1-1 / \nu}-\beta_{I}\left(C E_{t}^{I}\right)^{1-1 / \nu}\right) \text { for } \nu>1 \\
\left(1-\beta_{I}\right) \log \left(\hat{C}_{t}^{I}\right)+\beta_{I} \log \left(C E_{t}^{I}\right)-\log (x)-\left(1-\beta_{I}\right) \text { if } \nu=1
\end{array}\right.
$$

Optimal Portfolio Choice The first-order condition for the short-term bond position is:

$$
\begin{aligned}
& \left(q_{t}^{f}+\tau^{\Pi} r_{t}^{f}-\kappa I_{\left\{\hat{B}_{t}^{I}<0\right\}}\right) \frac{\left(1-\beta_{I}\right)\left(\hat{V}_{t}^{I}\right)^{1 / \nu}}{\left(\hat{C}_{t}^{I}\right)^{1 / \nu}}= \\
& \lambda_{t}^{I} q_{t}^{f}+\beta_{I} \mathrm{E}_{t}\left[\left(e^{g_{t+1}} \tilde{\hat{V}}_{t+1}^{I}\right)^{-\sigma_{I}} \tilde{\hat{V}}_{W, t+1}^{I}\right]\left(C E_{t}^{I}\right)^{\sigma_{I}-1 / \nu}\left(\hat{V}_{t}^{I}\right)^{1 / \nu}
\end{aligned}
$$

where $\lambda_{t}^{I}$ is the Lagrange multiplier on the borrowing constraint (35).

The first order condition for loans is:

$$
\begin{aligned}
& \left(q_{t}^{m}+\tau^{\Pi} r_{t}^{m} F\right) \frac{\left(1-\beta_{I}\right)\left(\hat{V}_{t}^{I}\right)^{1 / \nu}}{\left(\hat{C}_{t}^{I}\right)^{1 / \nu}}=\lambda_{t}^{I} \xi q_{t}^{m}+\mu_{t}^{I} \\
& +\beta_{I} \mathrm{E}_{t}\left[\left(e^{g_{t+1}} \tilde{\hat{V}}_{t+1}^{I}\right)^{-\sigma_{I}} \tilde{\hat{V}}_{W, t+1}^{I}\left(M_{t+1}+\delta Z_{A}\left(\omega_{t+1}^{*}\right) q_{t+1}^{m}\right)\right]\left(C E_{t}^{I}\right)^{\sigma_{I}-1 / \nu}\left(\hat{V}_{t}^{I}\right)^{1 / \nu},
\end{aligned}
$$

where $\mu_{t}^{I}$ is the Lagrange multiplier on the no-shorting constraint for guaranteed loans (36).

\section{A.2.3 Marginal value of wealth and SDF}

Differentiating (41) gives the marginal value of wealth

$$
\tilde{\hat{V}}_{W, t}^{I}=\left(1-F_{\rho}\left(\rho_{t}^{*}\right)\right) \frac{\partial \hat{V}^{I}\left(\hat{W}_{t}^{I}, 0, \mathcal{S}_{t}^{I}\right)}{\partial \hat{W}_{t}^{I}}
$$

where

$$
\frac{\partial \hat{V}^{I}\left(\hat{W}_{t}^{I}, 0, \mathcal{S}_{t}^{I}\right)}{\partial \hat{W}_{t}^{I}}=\left(\hat{C}_{t}^{I}\right)^{-1 / \nu}\left(1-\beta_{I}\right)\left(\hat{V}^{I}\left(\hat{W}_{t}^{I}, 0, \mathcal{S}_{t}^{I}\right)\right)^{1 / \nu}
$$


The stochastic discount factor of intermediaries is therefore

$$
\mathcal{M}_{t, t+1}^{I}=\beta_{I} e^{-\sigma_{I} g_{t+1}}\left(\frac{\hat{V}^{I}\left(\hat{W}_{t+1}^{I}, 0, \mathcal{S}_{t+1}^{I}\right)}{C E_{t}^{I}}\right)^{-\left(\sigma_{I}-1 / \nu\right)}\left(\frac{\hat{C}_{t+1}^{I}}{\hat{C}_{t}^{I}}\right)^{-1 / \nu},
$$

and

$$
\tilde{\mathcal{M}}_{t, t+1}^{I}=\left(1-F_{\rho}\left(\rho_{t+1}^{*}\right)\right) \mathcal{M}_{t, t+1}^{I}
$$

\section{A.2.4 Euler Equations}

It is then possible to show that the FOC with respect to $\hat{B}_{t}^{I}$ and $\hat{A}_{t+1}^{I}$, respectively, are:

$$
\begin{aligned}
q_{t}^{f}\left(1-\tilde{\lambda}_{t}^{I}\right) & =\mathrm{E}_{t}\left[\tilde{\mathcal{M}}_{t, t+1}^{I}\right]+\kappa I_{\left\{\hat{B}_{t}^{I}<0\right\}}-\tau^{\Pi} r_{t}^{f}, \\
q_{t}^{m}\left(1-\xi \tilde{\lambda}_{t}^{I}\right) & =\tilde{\mu}_{t}^{I}+\mathrm{E}_{t}\left[\tilde{\mathcal{M}}_{t, t+1}^{I}\left(\tilde{M}_{t+1}+\delta Z_{A}\left(\omega_{t+1}^{*}\right) q_{t+1}^{m}\right)\right] .
\end{aligned}
$$

\section{A.3 Savers}

\section{A.3.1 Statement of stationary problem}

For savers, we define the following transformed variables:

$$
\left\{\hat{W}_{t}^{S}, \hat{C}_{t}^{S}, \hat{B}_{t}^{S}, \hat{G}_{t}^{T, S}\right\} .
$$

Let $\mathcal{S}_{t}^{S}=\left(g_{t}, \sigma_{\omega, t}, \hat{K}_{t}^{B}, \hat{A}_{t}^{B}, \hat{W}_{t}^{I}, \hat{B}_{t-1}^{G}\right)$ be the saver's state vector capturing all exogenous state variables. Scaling by productivity, the stationary problem of the saver - after the intermediary has made default her decision and the utility cost of default is realized - is:

$$
\hat{V}^{S}\left(\hat{W}_{t}^{S}, \mathcal{S}_{t}^{S}\right)=\max _{\left\{\hat{C}_{t}^{S}, \hat{B}_{t}^{S}\right\}}\left\{\left(1-\beta_{S}\right)\left[\hat{C}_{t}^{S}\right]^{1-1 / \nu}+\beta_{S} \mathrm{E}_{t}\left[\left(e^{g_{t+1}} \tilde{\hat{V}}^{S}\left(\hat{W}_{t+1}^{S}, \mathcal{S}_{t+1}^{S}\right)\right)^{1-\sigma_{S}}\right]^{\frac{1-1 / \nu}{1-\sigma_{S}}}\right\}^{\frac{1}{1-1 / \nu}}
$$

subject to

$$
\begin{aligned}
\hat{C}_{t}^{S} & =\left(1-\tau_{t}^{S}\right) \hat{w}_{t}^{S} \bar{L}^{S}+\hat{G}_{t}^{T, S}+\hat{W}_{t}^{S}-q_{t}^{f} \hat{B}_{t}^{S} \\
\hat{W}_{t+1}^{S} & =e^{-g_{t+1}} \hat{B}_{t}^{S} \\
\hat{B}_{t}^{S} & \geq 0 \\
\mathcal{S}_{t+1}^{S} & =h\left(\mathcal{S}_{t}^{S}\right)
\end{aligned}
$$

As before, we will drop the arguments of the value function and denote marginal values of 
wealth and mortgages as:

$$
\begin{aligned}
\hat{V}_{t}^{S} & \equiv \hat{V}_{t}^{S}\left(\hat{W}_{t}^{S}, \mathcal{S}_{t}^{S}\right), \\
\hat{V}_{W, t}^{S} & \equiv \frac{\partial \hat{V}_{t}^{S}\left(\hat{W}_{t}^{S}, \mathcal{S}_{t}^{S}\right)}{\partial \hat{W}_{t}^{S}},
\end{aligned}
$$

Denote the certainty equivalent of future utility as:

$$
C E_{t}^{S}=\mathrm{E}_{t}\left[\left(e^{g_{t+1}} \tilde{\hat{V}}^{S}\left(\hat{W}_{t}^{S}, \mathcal{S}_{t}^{S}\right)\right)^{1-\sigma_{S}}\right]
$$

Like borrower-entrepreneurs, savers must take into account the intermediary's default decisions and the realization of the utility penalty of default. Therefore the marginal value of wealth is:

$$
\tilde{\hat{V}}_{W, t}^{S}=F_{\rho}\left(\rho_{t}^{*}\right) \frac{\partial V^{S}\left(\hat{W}_{t}^{S}, \mathcal{S}_{t}^{S}\left(\rho_{t}<\rho_{t}^{*}\right)\right)}{\partial \hat{W}_{t}^{S}}+\left(1-F_{\rho}\left(\rho_{t}^{*}\right)\right) \frac{\partial V^{S}\left(\hat{W}_{t}^{S}, \mathcal{S}_{t}^{S}\left(\rho_{t}>\rho_{t}^{*}\right)\right.}{\partial \hat{W}_{t}^{S}} .
$$

\section{A.3.2 First-order conditions}

The first-order condition for the short-term bond position is:

$$
q_{t}^{f}\left(\hat{C}_{t}^{S}\right)^{-1 / \nu}\left(1-\beta_{S}\right)\left(\hat{V}_{t}^{S}\right)^{1 / \nu}=\lambda_{t}^{S}+\beta_{S} \mathrm{E}_{t}\left[\left(e^{g_{t+1}} \tilde{\hat{V}}_{t+1}^{S}\right)^{-\sigma_{S}} \tilde{\hat{V}}_{W, t+1}^{S}\right]\left(C E_{t}^{S}\right)^{\sigma_{S}-1 / \nu}\left(\hat{V}_{t}^{S}\right)^{1 / \nu}
$$

where $\lambda_{t}^{S}$ is the Lagrange multiplier on the no-borrowing constraint (48).

\section{A.3.3 Marginal Values of State Variables and SDF}

Marginal value of wealth is:

$$
\hat{V}_{W, t}^{S}=\left(\hat{C}_{t}^{S}\right)^{-1 / \nu}\left(1-\beta_{S}\right)\left(\hat{V}_{t}^{S}\right)^{1 / \nu}
$$

and for the continuation value function:

$$
\tilde{\hat{V}}_{W, t}^{S}=F_{\rho}\left(\rho_{t}^{*}\right) \frac{\partial V^{S}\left(\hat{W}_{t}^{S}, \mathcal{S}_{t}^{S}\left(\rho_{t}<\rho_{t}^{*}\right)\right)}{\partial \hat{W}_{t}^{S}}+\left(1-F_{\rho}\left(\rho_{t}^{*}\right)\right) \frac{\partial \hat{V}^{S}\left(\hat{W}_{t}^{S}, \mathcal{S}_{t}^{S}\left(\rho_{t}>\rho_{t}^{*}\right)\right.}{\partial \hat{W}_{t}^{S}} .
$$

Defining the SDF in the same fashion as we did for the borrower, we get:

$$
\mathcal{M}_{t, t+1}^{S}\left(\rho_{t}\right)=\beta_{S} e^{-\sigma_{S} g_{t+1}}\left(\frac{\hat{V}_{t+1}^{S}}{C E_{t}^{S}}\right)^{-\left(\sigma_{S}-1 / \nu\right)}\left(\frac{\hat{C}_{t+1}^{S}}{\hat{C}_{t}^{S}}\right)^{-1 / \nu}
$$

and

$$
\tilde{\mathcal{M}}_{t, t+1}^{S}=F_{\rho}\left(\rho_{t+1}^{*}\right) \mathcal{M}_{t, t+1}^{S}\left(\rho_{t+1}<\rho_{t+1}^{*}\right)+\left(1-F_{\rho}\left(\rho_{t+1}^{*}\right)\right) \mathcal{M}_{t, t+1}^{S}\left(\rho_{t+1}>\rho_{t+1}^{*}\right)
$$




\section{A.3.4 Euler Equations}

Combining the first-order condition for short-term bonds (50) with the marginal value of wealth, and the SDF, we get the Euler equation for the short-term bond:

$$
q_{t}^{f}=\tilde{\lambda}_{t}^{S}+\mathrm{E}_{t}\left[\tilde{\mathcal{M}}_{t, t+1}^{S}\right]
$$

where $\tilde{\lambda}_{t}^{S}$ is the original multiplier $\lambda_{t}^{S}$ divided by the marginal value of wealth.

\section{A.4 Steady State}

This subsection outlines the calculation of the steady state of the deterministic version of the model (without aggregate shocks). The calculations directly operate on the stationary variables and omit the "hats".

Production Function The stationary version of the model has the production function

$$
Y=K^{1-\alpha} L^{\alpha}
$$

where $L=\left(L^{B}\right)^{\gamma_{B}}\left(L^{I}\right)^{\gamma_{I}}\left(L^{S}\right)^{\gamma_{S}}$.

From the first-order conditions for labor demand (27) we get for steady state wages

$$
w^{j}=\alpha \gamma_{j} \frac{L}{L^{j}}\left(\frac{K^{B}}{L}\right)^{1-\alpha} .
$$

By the usual derivations for CRS production functions this implies

$$
w^{j} L^{j}=\alpha \gamma_{j} Y
$$

and

$$
Y-\sum_{j} w^{j} L^{j}=(1-\alpha) Y
$$

Borrower Leverage Assuming a binding leverage constraint for borrower-entrepreneurs, the steady state of the model can be reduced to two nonlinear equations in the bond price $q^{m}$ and the default threshold $\omega^{*}$. The two equations that constitute the system for characterizing equilibrium are marked by (S1) and (S2) below.

If the constraint is binding we get

$$
\phi p Z_{K}\left(\omega^{*}\right) K^{B}=F A^{B},
$$

which we can substitute into the first-order condition for the default threshold (26) to yield

$$
\omega^{*}=\frac{\phi Z_{K}\left(\omega^{*}\right)}{e^{g}\left(1+\phi \lambda^{B}\right)} \frac{1-(1-\theta) \tau_{\Pi}^{B}+\delta q^{m}}{F} .
$$


The equation above is a nonlinear equation in $\omega^{*}$.

Capital Price and Investment We can use the first-order condition for investment $X$ and the market clearing condition for capital to express investment and the capital price $p$ as functions of parameters and $\omega_{*}$. First, rewriting the FOC for investment, we get

$$
X=\left[\left(e^{g}-\mu_{\omega}\right)+\frac{p-1}{\psi}\right] K^{B} .
$$

Substituting this into the capital market clearing condition and eliminating $K^{B}$ from both sides gives

$$
1=e^{-g}\left[Z_{K}+(1-\zeta)\left(\mu_{\omega}-Z_{K}\right)+e^{g}-\mu_{\omega}-\frac{1-p}{\psi}\right]
$$

which can be solved for the price

$$
p=1+\psi \zeta\left(\mu_{\omega}-Z_{K}\right) .
$$

Reinserting this into the expression for $X$ gives

$$
X=\left[e^{g}+\zeta\left(\mu_{\omega}-Z_{K}\right)-\mu_{\omega}\right] K^{B}
$$

Household SDFs The (stochastic) discount factors of households reduce to

$$
\tilde{\beta}_{j}=\beta_{j} e^{-g / \nu} .
$$

Capital Stock and Borrower Consumption We can solve the borrower-entrepreneurs first-order condition for next period's debt (30) to get an expression for the Lagrange multiplier on the leverage constraint

$$
\lambda^{B}=1-\tilde{\beta}_{B} Z_{A}\left(\frac{1-(1-\theta) \tau_{\Pi}^{B}}{q^{m}}+\delta\right) .
$$

We can further rewrite $\Psi_{K}$ as

$$
\Psi_{K}=-(p-1)\left(e^{g}-\mu_{\omega}+\frac{p-1}{2 \psi}\right)
$$

using that $X / K^{B}=e^{g}-\mu_{\omega}+(p-1) / \psi$.

Plugging this into the FOC for capital (31) gives

$p=\tilde{\beta}_{B}\left[p\left(Z_{K}\left(1+\phi \lambda^{B}\right)+\tau_{\Pi}^{B} Z_{A} \delta_{K}\right)+(1-\alpha)\left(1-\tau_{\Pi}^{B}\right)\left(\frac{K^{B}}{L}\right)^{-\alpha}+(p-1)\left(e^{g}-\mu_{\omega}+\frac{p-1}{2 \psi}\right)\right]$. 
This equation can be solved for $K^{B}$ as a function of labor input $L$

$$
K^{B}=\left(\frac{(1-\alpha)\left(1-\tau^{\Pi}\right) \tilde{\beta}_{B}}{p\left[1-\tilde{\beta}_{B}\left(Z_{K}\left(1+\phi \lambda^{B}\right)+\tau_{\Pi}^{B} Z_{A} \delta_{K}\right)\right]-\tilde{\beta}_{B}(p-1)\left(e^{g}-\mu_{\omega}+\frac{p-1}{2 \psi}\right)}\right)^{1 / \alpha} L .
$$

Since $L$ only depends on parameters, we can therefore now also compute output

$$
Y=\left(\frac{(1-\alpha)\left(1-\tau^{\Pi}\right) \tilde{\beta}_{B}}{p\left[1-\tilde{\beta}_{B}\left(Z_{K}\left(1+\phi \lambda^{B}\right)+\tau_{\Pi}^{B} Z_{A} \delta_{K}\right)\right]-\tilde{\beta}_{B}(p-1)\left(e^{g}-\mu_{\omega}+\frac{p-1}{2 \psi}\right)}\right)^{(1-\alpha) / \alpha} L .
$$

We can then use the solution for investment and the binding borrowing constraint to compute borrower consumption from the budget constraint.

Savers and Riskfree Bond Price Savers' FOC for holdings of risk free debt determines the risk free bond price

$$
q=\tilde{\beta}_{S}
$$

Intermediary The intermediary's FOC for risk free debt implies

$$
\lambda^{I}=1-\frac{\tilde{\beta}_{I}-\tau_{\Pi}^{I} r^{f}}{q} .
$$

With $\tilde{\beta}_{I}=\tilde{\beta}_{S}$, and using $r^{f}=1 / q-1=1 / \tilde{\beta}_{S}-1$, we get

$$
\lambda^{I}=\frac{\tau_{\Pi}^{I}}{\tilde{\beta}_{I}}\left(\frac{1}{\tilde{\beta}_{I}}-1\right) .
$$

By market clearing in the market for loans to borrower-entrepreneurs we have $A^{I}=A^{B}=$ $\phi p K^{B} / q^{m}$, and then using the intermediary's binding leverage constraint

$$
q B^{I}=-\xi q^{m} A^{I}=-\xi \phi p K^{B}
$$

Intermediary wealth is therefore

$$
W^{I}=e^{-g} A^{I}\left[\tilde{M}+q^{m}\left(\delta Z_{A}-\frac{\xi}{q}\right)\right],
$$

and intermediary consumption is

$$
C^{I}=\alpha \gamma_{I}\left(1-\tau^{I}\right) Y+G^{I}+W^{I}-A^{I}\left[q^{m}(1-\xi(q-\kappa))-\tau_{\Pi}^{I} r^{f} \xi q^{m} / q\right] .
$$

The bond price $q^{m}$ is determined by the intermediary's FOC for loans to borrowers

$$
q^{m}=\frac{\tilde{\beta}_{I} \tilde{M}}{1-\tilde{\beta}_{I} \delta Z_{A}-\xi \lambda^{I}},
$$


with $\tilde{M}$ given by

$$
\tilde{M}=Z_{A}\left(1-(1-\theta) \tau_{\Pi}^{I}\right)+\frac{(1-\zeta)\left(\mu_{\omega}-Z_{K}\right) p K^{B}}{A^{B}} .
$$

Government Government revenues are

$T=\left[\alpha\left(\sum_{j} \gamma_{j} \tau^{j}\right)+(1-\alpha) \tau_{\Pi}^{B}\right] Y-A^{B}\left[(1-\theta) Z_{A}\left(\tau_{\Pi}^{B}-\tau_{\Pi}^{I}\right)+\xi \frac{q^{m}}{q}\left(\tau_{\Pi}^{I}-\kappa\right)\right]-\tau_{\Pi}^{B} Z_{A} \delta_{K} p K^{B}$.

Assuming zero transfers to households $\left(G^{B}=G^{I}=G^{S}=0\right)$, the only difference between revenues and wasteful spending $G^{O}$ are interest payments on the government debt to savers:

$$
G^{O}=T-\left(e^{-g}-q\right) B^{G},
$$

for some fixed $B^{G}$ that is indeterminate in the non-stochastic version of the model.

Saver Consumption From market clearing for risk free debt we know that $B^{S}=B^{G}-B^{I}$, and saver consumption is

$$
C^{S}=\alpha \gamma_{S}\left(1-\tau^{S}\right) Y+G^{S}+\left(e^{-g}-q\right) B^{S} .
$$

Resource Constraint The steady state allocation needs to satisfy

$$
C^{B}+C^{I}+C^{S}=Y-G^{O}-e^{-g}(X+\Psi) .
$$

\section{B Calibration Appendix}

\section{B.1 Long-term corporate Bonds}

Our model's corporate bonds are geometrically declining perpetuities, and as such have no principal. The issuer of one unit of the bond at time $t$ promises to pay the holder 1 at time $t+1, \delta$ at time $t+2, \delta^{2}$ at time $t+3$, and so on. Issuers must hold enough capital to collateralize the face value of the bond, given by $F=\frac{\theta}{1-\delta}$, a constant parameter that does not depend on any state variable of the economy. Real life bonds have a finite maturity and a principal payment. They also have a vintage (year of issuance), whereas our bonds combine all vintages in one variable. This appendix explains how to map the geometric bonds in our model into real-world bonds by choosing values for $\delta$ and $\theta$.

Our model's corporate loan/bond refers to the entire pool of all outstanding corporate loans/bonds. To proxy for this pool, we use investment-grade and high-yield indices constructed by Bank of America Merill Lynch (BofAML) and Barclays Capital (BarCap). For the BofAML indices ${ }^{23}$ we obtain a time series of monthly market values, durations (the sensitivity

\footnotetext{
${ }^{23}$ Datastream Codes LHYIELD and LHCCORP for investment grade and high-yield corporate bonds, respectively
} 
of prices to interest rates), weighted-average maturity (WAM), and weighted average coupons (WAC) for January 1997 until December 2015. For the BarCap indices ${ }^{24}$ we obtain a time series of option-adjusted spreads over the Treasury yield curve.

First, we use market values of the BofAML investment grade and high-yield portfolios to create an aggregate bond index and find its mean WAC $c$ of $5.5 \%$ and WAM $T$ of 10 years over our time period. We also add the time series of OAS to the constant maturity treasury rate corresponding to that period's WAM to get a time series of bond yields $r_{t}$. Next, we construct a plain vanilla corporate bond with a semiannual coupon and maturity equal to the WAC and WAM of the aggregate bond index, and compute the price for $\$ 1$ par of this bond for each yield:

$$
P^{c}\left(r_{t}\right)=\sum_{i=1}^{2 T} \frac{c / 2}{\left(1+r_{t}\right)^{i / 2}}+\frac{1}{\left(1+r_{t}\right)^{T}}
$$

We can write the steady-state price of a geometric bond with parameter $\delta$ as

$$
P^{G}\left(r_{t}\right)=\frac{1}{1+r_{t}}\left[1+\delta P^{G}\left(r_{t}\right)\right]
$$

Solving for $P^{G}\left(y_{t}\right)$, we get

$$
P^{G}\left(r_{t}\right)=\frac{1}{1+r_{t}-\delta}
$$

The calibration determines how many units $X$ of the geometric bond with parameter $\delta$ one needs to sell to hedge one unit of plain vanilla bond $P^{c}$ against parallel shifts in interest rates, across the range of historical yields:

$$
\min _{\delta, X} \sum_{t=1997.1}^{2015.12}\left[P^{c}\left(r_{t}\right)-X P^{G}\left(r_{t} ; \delta\right)\right]^{2}
$$

We estimate $\delta=0.937$ and $X=12.9$, yielding an average pricing error of only $0.41 \%$. This value for $\delta$ implies a time series of durations $D_{t}=-\frac{1}{P_{t}^{G}} \frac{d P_{t}^{G}}{d r_{t}}$ with a mean of 6.84 .

To establish a notion of principal for the geometric bond, we compare it to a durationmatched zero-coupon bond i.e. borrowing some amount today (the principal) and repaying it $D_{t}$ years from now. The principal of this loan is just the price of the corresponding $D_{t}$ maturity zero-coupon bond $\frac{1}{\left(1+r_{t}\right)^{D_{t}}}$

We set the "principal" $F$ of one unit of the geometric bond to be some fraction $\theta$ of the undiscounted sum of all its cash flows $\frac{\theta}{1-\delta}$, where

$$
\theta=\frac{1}{N} \sum_{t=1997.1}^{2015.12} \frac{1}{\left(1+r_{t}\right)^{D_{t}}}
$$

We get $\theta=0.582$ and $F=9.18$.

\footnotetext{
${ }^{24}$ They are named C0A0 and H0A0 for investment grade and high-yield corporate bonds, respectively.
} 